\title{
A review on half a century of experience in rate of penetration management: Application of analytical, semi-analytical and empirical models
}

\author{
Mohammad Najjarpour ${ }^{1}$, Hossein Jalalifar $^{2}$, Saeid Norouzi-Apourvari ${ }^{2 \oplus *}$ \\ ${ }^{1}$ National Iranian South Oilfields Company, Ahvaz, Iran \\ ${ }^{2}$ Department of Petroleum Engineering, Shahid Bahonar University of Kerman, Kerman, Iran
}

\section{Keywords:}

Rate of penetration

analytical models

semi-analytical models

empirical correlations

Cited as:

Najjarpour, M., Jalalifar, H.,

Norouzi-Apourvari, S. A review on half a

century of experience in rate of

penetration management: Application of

analytical, semi-analytical and empirical

models. Advances in Geo-Energy

Research, 2021, 5(3): 252-273, doi:

10.46690/ager.2021.03.03

\begin{abstract}
:
Rate of penetration management is a matter of importance in drilling operations and it has been used in some research studies. Although conventional approaches for rate of penetration management are mainly focused on analytical and semi-analytical models, several correlations have also been developed for this purpose. The history of rate of penetration management studies extends back more than half a century and ever since, research interest in this concept has never declined, making it a focus of industry and academic studies. In this article, some of these studies are reviewed to achieve a better understanding of rate of penetration management concept, its financial benefits and also its research capacities. This review reveals the most common rate of penetration management methods which applied analytical, semi-analytical and empirical correlations in different fields around the world. In other words, the main purpose of this study is to evaluate the research studies in which different models and correlations have been used as the main approach for rate of penetration management. Based on the results of this review, the best models for performing rate of penetration management studies and the best objective functions for optimization algorithms are introduced.
\end{abstract}

\section{Introduction}

Rate of penetration (ROP) plays a pivotal role in controlling drilling efficiency and operational costs. Low ROP causes an increase of drilling time, leading to increment of drilling expenditure and massive economical losses (Liu et al., 2014; Anemangely et al., 2018). These costs refer to drilling rig and crew and the efficiency of these parameters which directly relate to the working time (Mirzaei-Paiaman et al., 2009). On the other hand, increasing ROP more than its optimum value results in drilling malfunction, such as excessive vibration, fast bit warming, and bit dullness (Barbosa et al., 2019; Hegde et al., 2019). Such incidents force the drilling crew to stop the operation and change the bit more often, resulting in the increase of drilling time and costs. There is an optimum value for ROP which decreases these two items while mitigating the drilling vibrations (Akbari et al., 2011; Shi et al., 2016). If ROP exceeds its optimum value, managing the well pressure becomes harder and the possibility of kick flow will increase (Mammadov et al., 2015).

To avoid any confusion, it should be noted that the term "ROP" in this study refers to the instantaneous ROP with routine field units, while "optimum ROP" is the fastest ROP without causing incidents or excessive drilling vibrations. In addition, the term "related parameters" represents the group of controllable parameters which are frequently used for changing the consequent ROP, such as weight on bit (WOB), rotational speed, mud weight, bit torque, etc.

A complete ROP management project consists of different subjects including the prediction and optimization of ROP and its related parameters and also some instructions about the operating parameters to achieve the optimum ROP (Wiktorski et al., 2017). In recent years, some drilling optimization software and expert systems have been developed to facilitate this process (e.g., Hegde et al., 2015; Mantha and Samuel, 2016;

\section{Yandy} Scientific Press

${ }^{*}$ Corresponding author.

E-mail address: mohammad.najjarpour@gmail.com (M. Najjarpour); jalalifar@uk.ac.ir (H. Jalalifar);

snorouzi@uk.ac.ir (S. Norouzi-Apourvari).

2207-9963 (c) The Author(s) 2021.

Received March 30, 2021; revised May 11, 2021; accepted May 12, 2021; available online May 15, 2021.
} 
Hegde and Gray, 2017; Najjarpour et al., 2020); however, most of these expert systems do not focus on analytical, semianalytical and empirical ROP models.

The importance of ROP management has encouraged researchers to conduct numerous projects and research studies in this regard and it is also the main motivation for the authors to perform the in-hand study. Not only in definitions and concepts (Mathis et al., 2007; Mensa-Wilmot et al., 2010), but also for the application purposes (Al-Betairi et al., 1988; Nygaard and Hareland, 2007; Eren and Ozbayoglu, 2010; Mostofi et al., 2010; Nascimento et al., 2015), this topic has attracted lots of attention in recent years. The objective of this study is to review the history of ROP models and to explain the results of performance comparison studies and field applications. To be more specific, this study aims to highlight the field applications of analytical, semi-analytical and empirical ROP management methods and compare their limitations and capabilities. Among all of the research studies related to ROP management, 45 studies are selected which have used analytical, semi-analytical and empirical ROP models as the main approach for ROP management. For the sake of brevity, other ROP management approaches (i.e., managed pressure drilling, mechanical specific energy, artificial intelligence algorithm and bit management) are not discussed here.

The review initiates with explaining the main parameters affecting ROP in section 2, and is being followed by expressing the equations regarding the most important and widely-used ROP models (e.g., Bingham (1964), Bourgoyne and Young (1974), and Warren (1987)) in section 3. In section 4 , the history of developing ROP models are reviewed for different categories of roller cone bits (RCB), polycrystalline diamond compact (PDC) bits and also empirical ROP correlations. Moreover, a special review on the ROP models developed for horizontal and deviated wells is performed in this section. In section 5, field applications and performance comparison studies by using different ROP models, as the main approach for ROP management, are illustrated. Section 6 is dedicated to the discussion about the statistics and observed review trends, and later on, section 7 concludes the whole study and summarizes all of the findings.

\section{Main parameters affecting ROP}

The factors affecting ROP can be categorized as rock characteristics, operational drilling parameters, mud properties, bit properties and design, bit hydraulics, bit worn and other problems associated with bit and drilling string. These parameters can be generally classified in two major groups of controllable and uncontrollable (environmental) parameters which are illustrated in Table 1 and briefly discussed in this section.

\subsection{Controllable parameters}

These factors are in control of the drillers and can be changed during drilling. In other words, they have more flexibly compared to uncontrollable parameters and they are more prone to be controlled and modified due to financial and geological conditions. Therefore, implementing the optimum
Table 1. Classification of different parameters affecting ROP (Fear, 1999).

\begin{tabular}{ll}
\hline $\begin{array}{l}\text { Controllable } \\
\text { Parameters }\end{array}$ & $\begin{array}{l}\text { Uncontrollable (Environmental) } \\
\text { Parameters }\end{array}$ \\
\hline Depth & Bit wear state \\
Formation properties & Bit design \\
Mud type & Weight on bit \\
Mud density & Bit rotational speed \\
Other mud properties & Mud flow rate \\
Bit size & Bit Hydraulics \\
- & Bit nuzzle size \\
\hline
\end{tabular}

values of these parameters would be more feasible, resulting in a faster and safer drilling operation. As such, controlling mud weight to prevent wellbore instability or mud kick, controlling WOB and bit rotational speed for stabilization of drill string and controlling mud flow rate for improving drilling hydraulics and well cleaning can be mentioned. In upcoming sub-sections, some of the most important controllable parameters such as WOB, bit rotational speed and mud rheological properties are discussed briefly; however, the controllable parameters affecting ROP are not limited to these factors.

\subsubsection{WOB}

This parameter directly affects ROP as it causes the bit to overcome the wedge or rocks being drilled. In fact, the force that a bit puts over a rock must exceed its compressional resistance to break it down. Hence, WOB is considered as one of the most significant parameters to be controlled during drilling. Fig. 1 depicts the relationship of WOB and ROP, which rejects the misconception of continuous increase of ROP with WOB.

As it can be seen in Fig. 1, in the primary stage of exerting WOB, bit penetrates into formation with a fast pace, making a nonlinear relationship between WOB and ROP. Afterwards, regardless of degree of rock softness, the relationship between these two parameters remains proportional as long as holecleaning is proper and complete. In fact, the straight-line re-

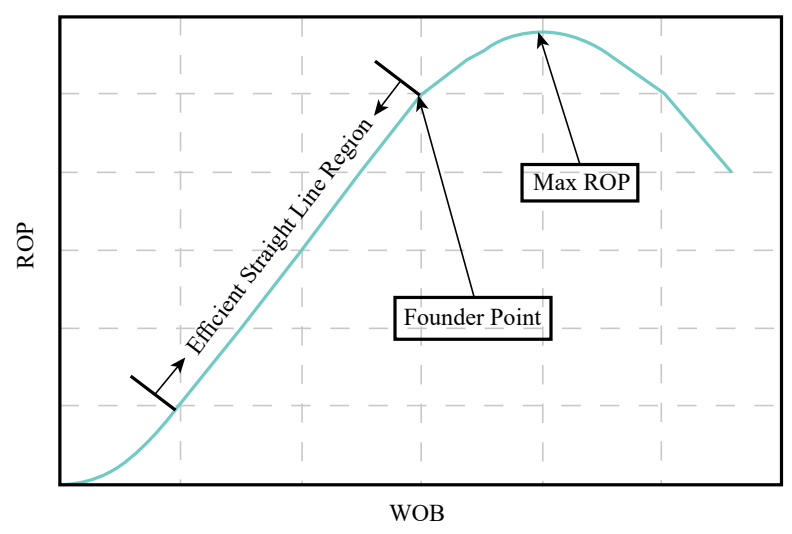

Fig. 1. The relationship between WOB and ROP. 
gion of the plot is where the bit is working with greatest efficiency. After this point which is called as the "floundering point", some sorts of inefficiency such as bit vibration, bit balling, or inadequate hole-cleaning happens and drilling cuttings cannot be removed from the hole perfectly. This results in waste of energy over re-drilling the debris instead of virgin rocks, which dwindles the effect of this parameter on ROP. At any WOB after maximum ROP, The trend would become reverse at a point which generating the debris excel their excavation and decreases ROP thereafter.

\subsubsection{Bit rotational speed}

Previous studies have shown that bit rotational speed has a proportional correlation with ROP in unconsolidated formations until the floundering point is reached. In consolidated or dense formations, however, ROP is less correlated with bit rotational speed, even before reaching the floundering point. After this point, further rock excavation would be more difficult due to inefficiency of hole-cleaning, until the maximum value of ROP is reached. Even in this segment, the increment of ROP with the increase of rotary speed is more severe in unconsolidated formations. Hence, it is better to adopt high rotational speeds in unconsolidated formations and low rotary speeds in consolidated ones. The correlation between these two parameters would be closer and more proportional by improvement of the hole-cleaning. As the rotary speed exceeds its maximum value, further augmentation of this parameter will not affect ROP anymore.

A typical plot of ROP versus bit rotational speed is depicted in Fig. 2. As mentioned before, ROP usually increases linearly with the increment of rotary speed (segment a-b). After the floundering point, the increase of ROP is decelerated by the augmentation of rotary speed (Segment b-c). After surpassing the maximum ROP (point $\mathrm{c}$ ), rotational speed has no noticeable influence on ROP. The poor response of ROP at high values of rotary speed is mostly attributed to less wellbore stability and enlargement of the wellbore, resulting in improper hole-cleaning.

\subsection{Uncontrollable parameters}

Adjustment of uncontrollable parameters is a challenging

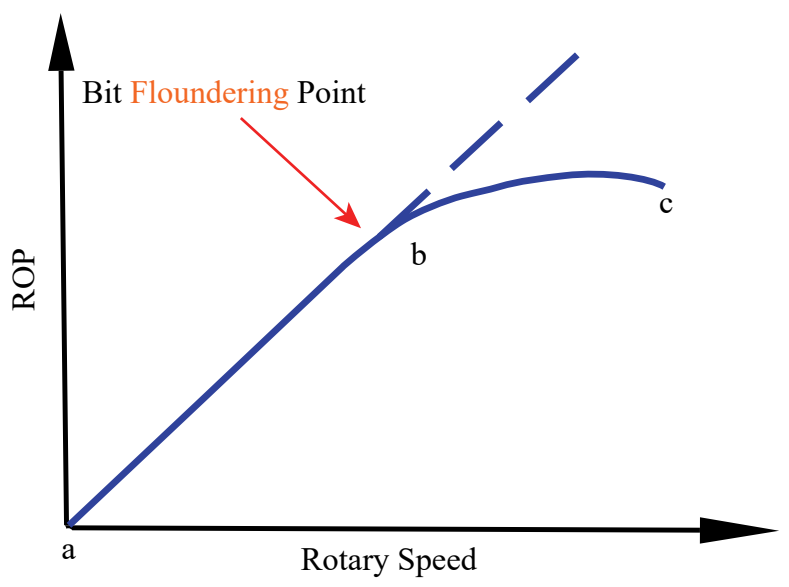

Fig. 2. The relationship between bit rotational speed and ROP. issue due to economic and geological reasons such as the rock formation which limits the selection of mud weight and type, wellbore azimuth and inclination, pore pressure gradient, unconfined compressive strength and principal stresses (Bani Mustafa et al., 2021). Rock type plays a pivotal role in the conditions and performance of drilling operation. Therefore, it is a must to take into account the factors regarding the rock and formation, despite of being unchangeable and free of drillers' control. Moreover, mud properties such as type and density depend on formation type and formation pressure are included in the category of uncontrollable or environmental parameters. The correlation of different mud rheology properties with ROP is expressed in the upcoming sub-section.

\subsubsection{Mud rheology properties}

Among different mud rheology parameters, mud viscosity, mud weight, filtration value, oil content and solids content can be mentioned as the most important factors in ROP management (Mirzaei-Paiaman et al., 2009). Generally, ROP increases with the decrement of viscosity, oil content, solids content and mud weight, while it increases with the augmentation of filtration. The reason for such behaviors basically refers to the effect of differential pressure on the bottom of the well. In this way, mud viscosity provides the hydraulic hits in the bit by controlling the pressure loss in drill pipes. What is more, the solid particles with the size of less than 1 micrometer prevent the filtration under the bit, resulting in decrement of ROP. Different behaviors of mud rheological parameters are illustrated in Fig. 3, in which, it is readily apparent that mud weight affects ROP more severely than other mud rheology parameters.

\section{Basics of analytical, semi-analytical and empirical ROP models}

In this section, some of the most important analytical-and semi-analytical ROP models are reviewed and their equations are explained. These models have been used in the postcoming studies more repeatedly.

\subsection{Bingham model}

Bingham (1964) proposed the following relation for calculating ROP:

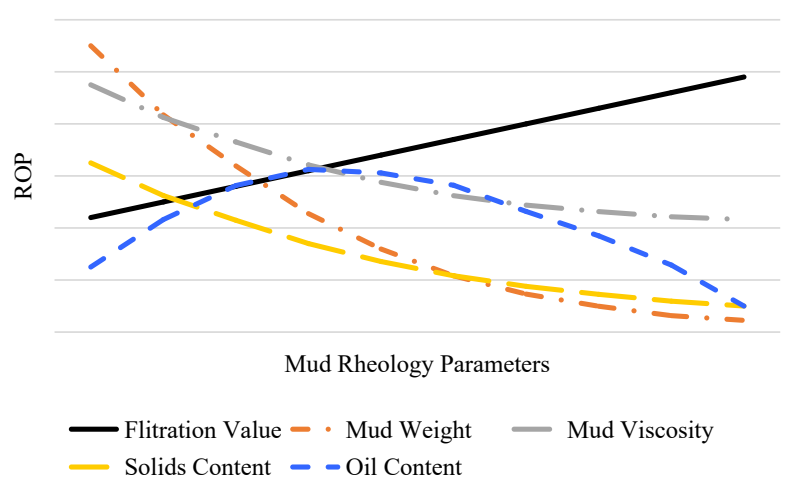

Fig. 3. The relationship between ROP and different mud rheology parameters. 


$$
R O P=K\left(\frac{W}{D_{b}}\right)^{x} N
$$

where $K$ is a formation-related constant, $x$ is the bit exponent, $N$ shows rotational speed (rpm), $W$ is weight on bit (lbf) and $D_{b}$ expresses the bit diameter (in).

\subsection{Bourgoyne and Young model}

Bourgoyne and Young (1974) proposed the following relation for calculating ROP, using RCB:

$$
R O P=f_{1} \times f_{2} \times f_{3} \times f_{4} \times f_{5} \times f_{6} \times f_{7} \times f_{8}
$$

These functions can be calculated by following equations:

$$
\begin{gathered}
f_{1}=e^{2.303 a_{1}} \\
f_{2}=e^{2.303 a_{2}(10000-D)} \\
f_{3}=e^{2.303 a_{3} T V D^{0.69}\left(g_{p}-9\right)} \\
f_{4}=e^{2.303 a_{4} T V D\left(g_{p}-E C D\right)} \\
f_{5}=\left[\frac{\left(\frac{W}{D_{b}}\right)-\left(\frac{W}{D_{b}}\right)_{t}}{4-\left(\frac{W}{D_{b}}\right)_{t}}\right]^{a_{5}} \\
f_{6}=\left(\frac{N}{60}\right)^{a_{6}} \\
f_{7}=e^{-a_{7} h} \\
f_{8}=\left(\frac{F_{j}}{1000}\right)^{a_{8}}
\end{gathered}
$$

where $T V D$ shows the true vertical depth ( $\mathrm{ft}$ ), $g_{p}$ is pore pressure gradient $(\mathrm{lbm} / \mathrm{gal}), E C D$ expresses the equivalent circulating density (lbf/gal), $\left(W / D_{b}\right)_{t}$ shows the threshold bit weight per inch of bit diameter at which the bit begins to drill (lbf/in), $N$ shows the rotational speed (rpm), $F_{j}$ is the jet impact force (lbf) and $h$ is the fractional bit tooth wear.

The function $f_{1}$ represents the effect of formation strength, bit type, mud type and solid contents which are not included in the model. This term is related to formation properties and it is expressed in the same units as ROP. The functions $f_{2}$ and $f_{3}$ model the effect of formation compaction and $f_{4}$ models the effect of pressure overbalance on ROP. The functions $f_{5}$ and $f_{6}$ model the effects of bit weight and rotary speed while $f_{7}$ models the effect of tooth wear and $f_{8}$ models the effect of bit hydraulics on ROP. The constants $a_{1}$ to $a_{8} \mathrm{~s}$ which are dependent to local drilling conditions, should be computed for each formation separately; by using prior drilling data from the field (Bourgoyne and Young, 1974).

\subsection{Warren model}

Warren (1987) derived an ROP model for drilling with tricone bits. This model has two different modes of "perfect cleaning" and "imperfect cleaning" to express different states of hole-cleaning and also consider the effects of drilling cuttings, and they are expressed herein:

For the case of "perfect cleaning":

$$
R O P=\left(\frac{a S^{2} D_{b}^{3}}{N^{b} W^{2}}+\frac{c}{N D_{b}}\right)^{-1}
$$

For the case of "imperfect cleaning":

$$
R O P=\left(\frac{a S^{2} D_{b}^{3}}{N^{b} W^{2}}+\frac{c}{N D_{b}}+\frac{c \mu \gamma_{f} D_{b}}{F_{j m}}\right)^{-1}
$$

where $a, b$ and $c$ are model constants. $S$ shows the confined compressive strength (psi), $D_{b}$ is the bit diameter (in), $N$ shows the rotational speed (rpm), $W$ is weight on bit (lbf), $\mu$ shows the plastic viscosity of the drilling fluid $(\mathrm{cP}), \gamma_{f}$ is the fluid specific gravity and $F_{j m}$ is the modified jet impact force (lbf).

\subsection{Hareland and Hoberock model}

Hareland and Hoberock (1993) modified the previous model of Warren (1987) and proposed the following equation as the "modified Warren model":

$$
R O P=W_{f}\left[f_{c}\left(P_{e}\right)\left(\frac{a S^{2} D_{b}^{3}}{N W^{2}}+\frac{b}{N D_{b}}\right)+\left(\frac{c D_{b} \rho \mu}{F_{j m}}\right)\right]^{-1}
$$

where $W_{f}$ is bit wear function and $f_{c}$ is called the "chip holddown function"; both of them can be calculated with the following calculations:

$$
\begin{gathered}
f_{c}\left(P_{e}\right)=c_{c}+a_{c}\left(P_{e}-120\right)^{b_{c}} \\
W_{f}=1-\frac{\Delta B G}{8}
\end{gathered}
$$

where $\triangle B G$ is the change in bit tooth wear. It can be calculated based on WOB, relative rock abrasiveness and confined rock strength with the following formula:

$$
\Delta B G=W_{c} \sum_{i=1}^{n} W_{i} N_{i} A r_{a b r_{i}} S_{i}
$$

Confined compressive strength is a function of pressure and lithology and can be calculated as:

$$
S=S_{0}\left(1+a_{s} P_{e}^{b_{s}}\right)
$$

where $S$ and $S_{0}$ are the confined and unconfined compressive strengths (psi), $P_{e}$ is the effective differential pressure (psi) and finally, $a_{s}$ and $b_{s}$ are the coefficients depend on formation permeability (Rampersad et al., 1994). These coefficients are shown in Table 2.

In these equations, $a, b$ and $c$ are model constants, $D_{b}$ is the bit diameter (in), $N$ shows the rotational speed (rpm), $W$ is weight on bit (lbf), $\mu$ shows mud plastic viscosity (cP), $\rho$ is drilling fluid density (lbf/gal), $W_{c}$ is the bit wear coefficient, 
Table 2. Chip Holddown Coefficients (Rampersad et al., 1994).

\begin{tabular}{lll}
\hline Formation & Permeable & Impermeable \\
\hline $\mathrm{a}_{c}$ & 0.00497 & 0.0141 \\
$\mathrm{~b}_{c}$ & 0.0757 & 0.470 \\
$\mathrm{c}_{c}$ & 0.103 & 0.569 \\
$\mathrm{a}_{s}$ & 0.0133 & 0.00432 \\
$\mathrm{~b}_{s}$ & 0.577 & 0.782 \\
\hline
\end{tabular}

$A r$ is relative abrasiveness and $F_{j m}$ is the modified jet impact force (lbf).

\subsection{Rastegar model}

Rastegar et al. (2008) presented another modified version of the Hareland and Hoberock (1993) model to increase its prediction accuracy in PDC bits. This physics-based equation is:

$$
R O P=W_{f}\left[\frac{14.14 W N \cos \alpha}{S D_{b} \tan \theta f_{c}\left(P_{e}\right)} \frac{a}{N^{b} W O B^{C}}\right]
$$

where $\alpha$ and $\theta$ are the siderake and backrake angles (degrees) of PDC cutter, respectively, and rest of the parameters are same as the previous equation of Hareland and Hoberock (1993).

\subsection{Al-abduljabbar correlation}

Al-abduljabbar et al. (2019) proposed the following ROP model by using a regression analysis:

$$
R O P=\frac{16.96 W^{a} N * T * S P P * Q}{D_{b}^{2} * U C S^{b} * \rho * \mu}
$$

where $a$ and $b$ are model coefficients and will be calculated by nonlinear regression (the authors proposed 0.85 and 1.16 for the values of these parameters, respectively), $W$ is weight on bit (Klbf), $N$ is bit rotational speed (rpm), $T$ is bit torque (Klb-ft), $S P P$ is standpipe pressure (psi), $Q$ is mud flowrate (gal/min), $D_{b}$ is the bit diameter (in), UCS shows the uniaxial compressive strength (psi), $\rho$ is the mud density (pcf) and $\mu$ represents the plastic viscosity (cP) (Barbosa et al., 2019).

\section{The history of ROP models}

Using traditional ROP models is a conventional approach in ROP management studies (Bezminabadi et al., 2017). Either as an assistant model for artificial intelligence algorithms or as a basic ROP management tool, they have been used repeatedly (Bahari and Baradaran Seyed, 2007a; Rastegar et al., 2008; Bataee et al., 2010; Sui et al., 2013; Formighieri and Freitas, 2015; Kutas et al., 2015; Soares et al., 2016; Hegde et al., 2019). In this section, the history of developing different ROP models is reviewed and they are categorized in different subsections of RCB and PDC bits and also empirical correlations. It should be noted that empirical correlations are developed for different types of RCB and PDC bits, but they are counted in a separate sub-section. Finally, several ROP models developed for horizontal and deviated wells are specifically reviewed at the end of the section.

\subsection{Different mechanisms and structures of $R C B$ and PDC bits}

The fundamental differences of RCB and PDC bits have resulted in totally different mechanisms of developing ROP models in the literature. RCB models are mostly semianalytical, requiring an adjustment after theoretical derivation, while most of PDC models are physics-based and derived by considering bit parameters. This variation in mechanisms has forced the authors to adopt different strategies when proposing new ROP models for each type, and this is why they are distinguished in this study. Some of these specific mechanisms along with special parameters implemented in this regard are introduced in this section.

\subsubsection{Cutting mechanism and structure of a typical $R C B$ bit}

Drilling with RCB bits consists of two fundamental operations. Craters are first formed under the bit teeth and the broken rock is then removed from these craters (Maurer, 1962). Crater formation mechanism is depicted in Fig. 4. The
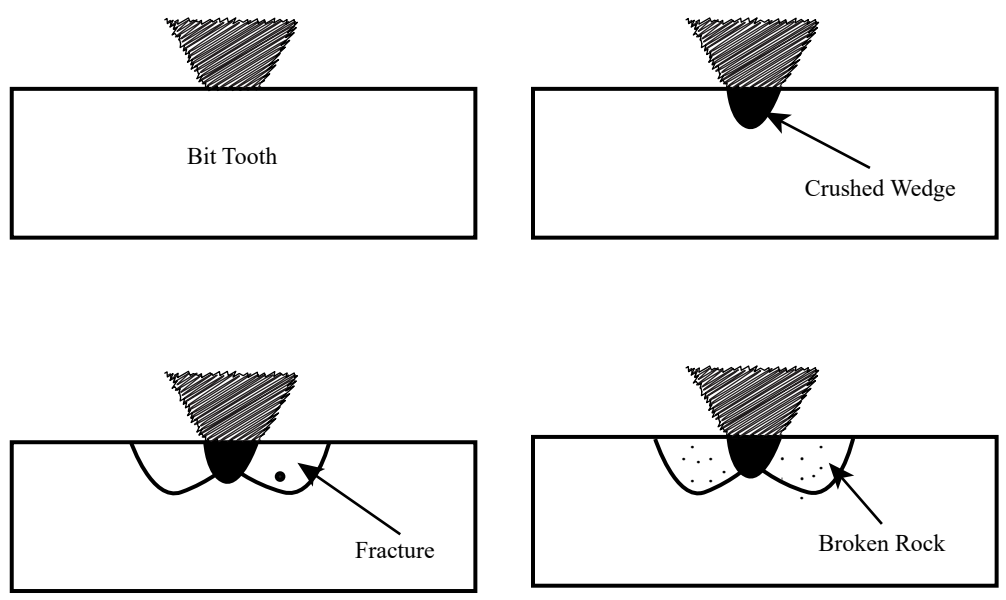

Fig. 4. Crater formation mechanism (Maurer, 1962). 


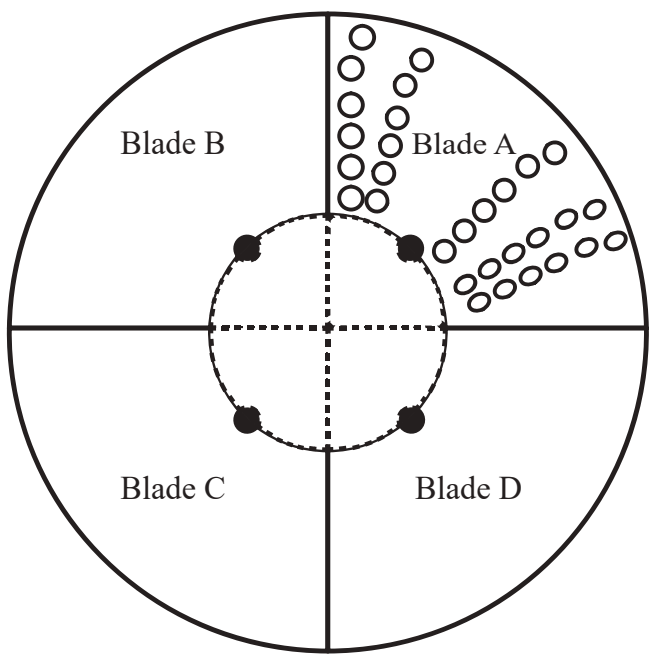

Fig. 5. Bottom view of a four-blade PDC bit (Peterson, 1976).

application of additional force to the bit tooth compresses the crushed materials and at sufficiently high forces, fractures initiate under the bit tooth and propagate to the rock surface (Maurer, 1962). A large portion of rock will be removed when there is a second free face for crater to fracture. Above this speed, the bit rotates so rapidly that all of the materials cannot be removed from the craters between impacts.

The craters are formed near or at the bottom of the wedge produced beneath the bit tooth as shown in Fig. 4; therefore, they form at some distance beneath the teeth. When craters are formed with a differential pressure across the rock, the broken material will be held in the craters by this differential pressure. If the bit cones are skewed, the teeth will drag through these cuttings and remove some of them from the craters. Because the broken material is held in the craters and the craters are formed near the bottom of the wedge, the increase in ROP produced by this dragging action would be largely due to better cleaning instead of actual breaking of virgin rock (Maurer, 1962). If the dragging action is a cleaning mechanism, it will not affect ROP in the perfect cleaning condition.

\subsubsection{Cutting mechanism and structure of a typical PDC bit}

A bottom view of a four-blade PDC bit is shown in Fig. 5. The position of four blades at various times during one rotation of a PDC bit is demonstrated in Fig. 6. For a fourblade PDC bit, four diamonds pass over the same point in each revolution of the bit. After rotating $90^{\circ}$ at each depth of penetration, the process should be repeated by advancing the bit into the formation. The actual advancing pattern of each diamond is better represented by a spiral (Peterson, 1976).

To penetrate the formation, the load applied to each diamond should exceed the formation resistance (Peterson, 1976). Fig. 7 shows a diamond drilling bit, in which the projected area is in contact with the rock. A uniform cut is achieved at maximum diamond penetration when adjacent-blade diamonds work together (Fig. 8). A bit layout for a two-blade PDC bit is illustrated in Fig. 9, in which each blade lays out as a helix for mathematical model representation. The staggered pattern of adjacent diamonds provide an overlap between diamonds (Peterson, 1976).

\subsection{Analytical and semi-analytical ROP models developed for $\mathrm{RCB}$ bits}

The chain of ROP models developed for RCB bits reaches to more than half a century ago. Firstly, Maurer (1962) proposed an equation for prediction of ROP for both "perfect cleaning" and also "imperfect cleaning" modes. The parameters included in this model are WOB, rotational speed, bit diameter and uniaxial compressive strength (UCS). Then, Galle and Woods (1963) proposed a new model by considering WOB, rotational speed, formation type and bit tooth resistance. This model has a basic assumption of ROP being mainly controlled by rotational speed and WOB. Later, Bingham (1964) modified the Maurer (1962) model to propose a new ROP model. Despite of its simplicity and neglecting the effect of hole-depth, this model was used in several ROP prediction studies (Bataee et al., 2010; Ayoub et al., 2017; Hegde et al., 2017). Mechem and Fullerton (1965) proposed an ROP model based on a drilling energy unit (i.e., $W O B * N$ ) which provided a basis for estimation of drilling operation costs, primary well management and ROP optimization process (Osgouei and Özbayoğlu, 2007).

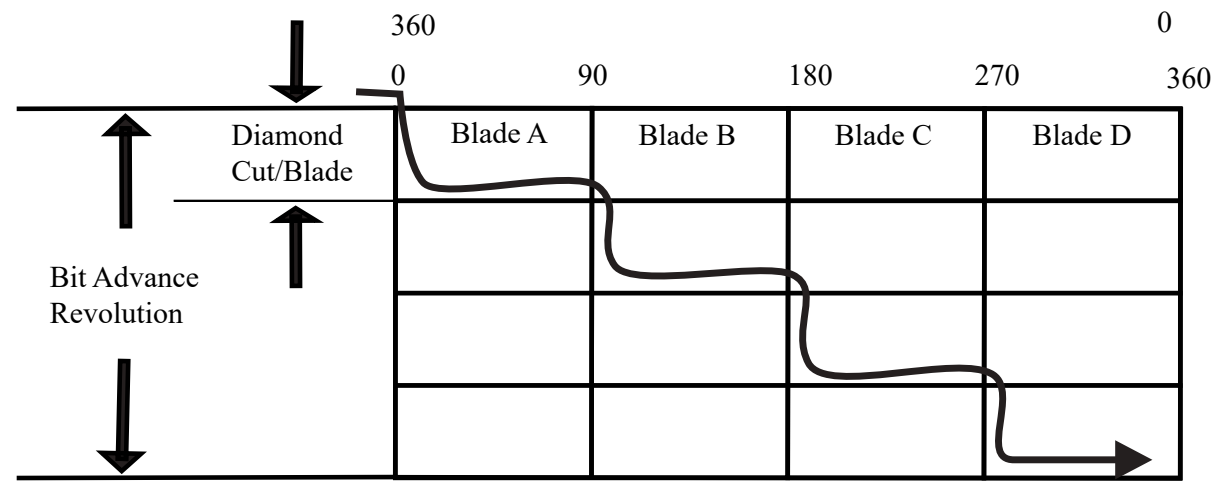

Expanded Cross Section of Hole Cut

Fig. 6. The concept of equivalent-blade (Peterson, 1976). 


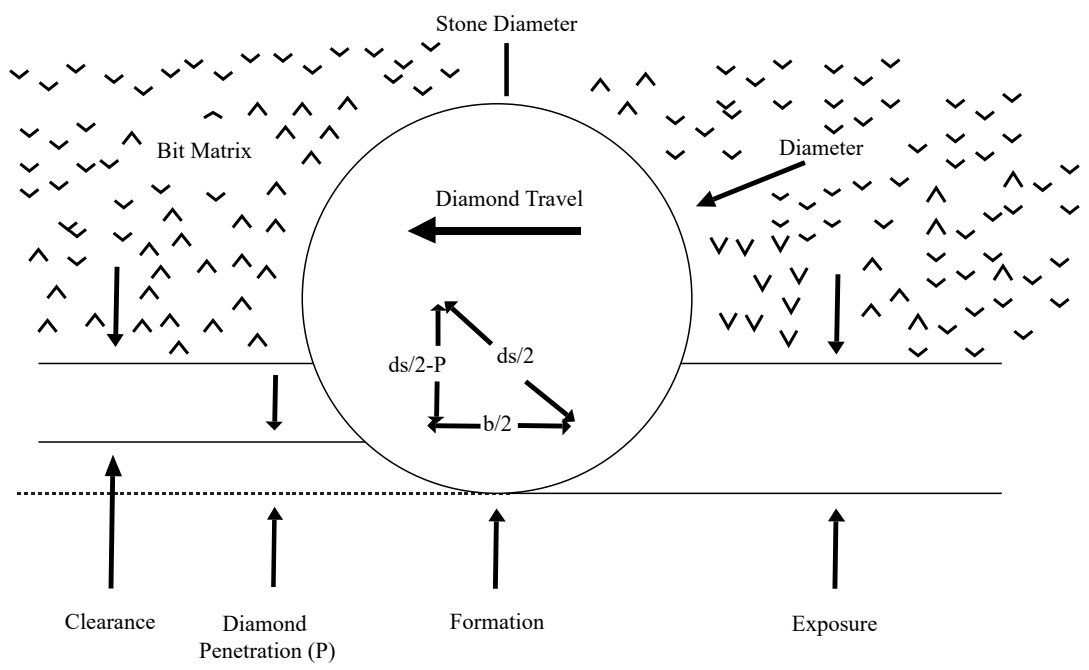

Fig. 7. Side view of an individual diamond cut (Peterson, 1976).

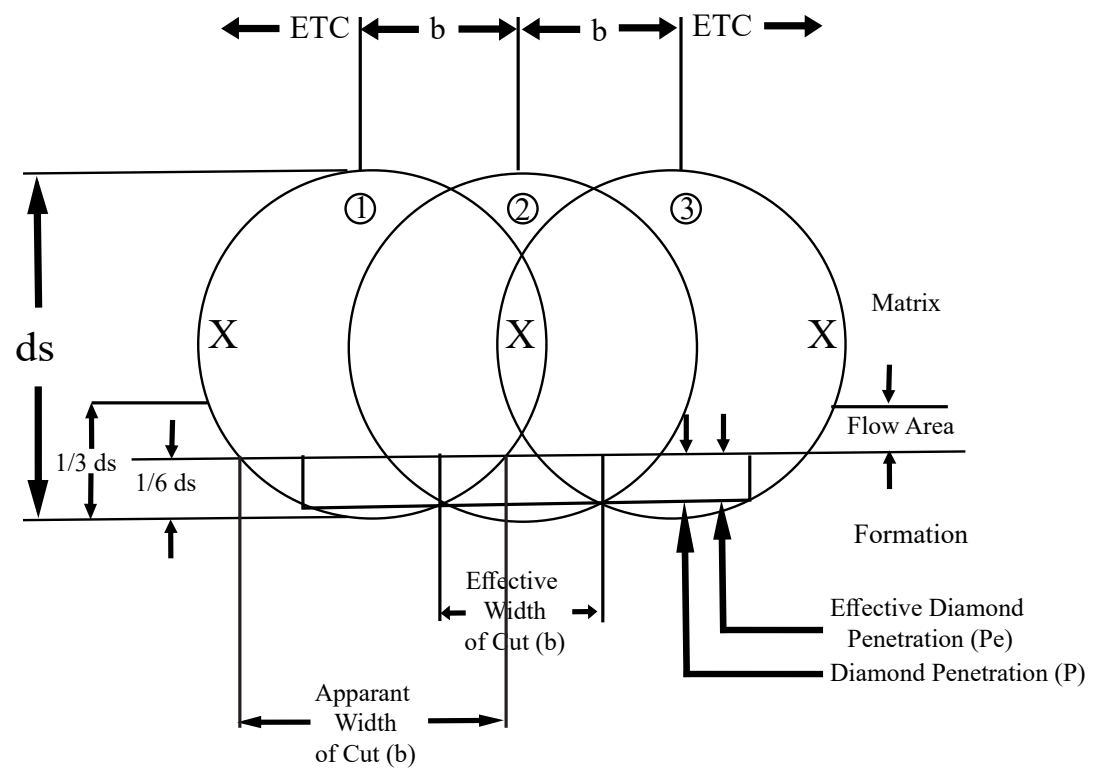

Fig. 8. Radial spacing between adjacent-blade diamonds for travel out of drawing (Peterson, 1976).

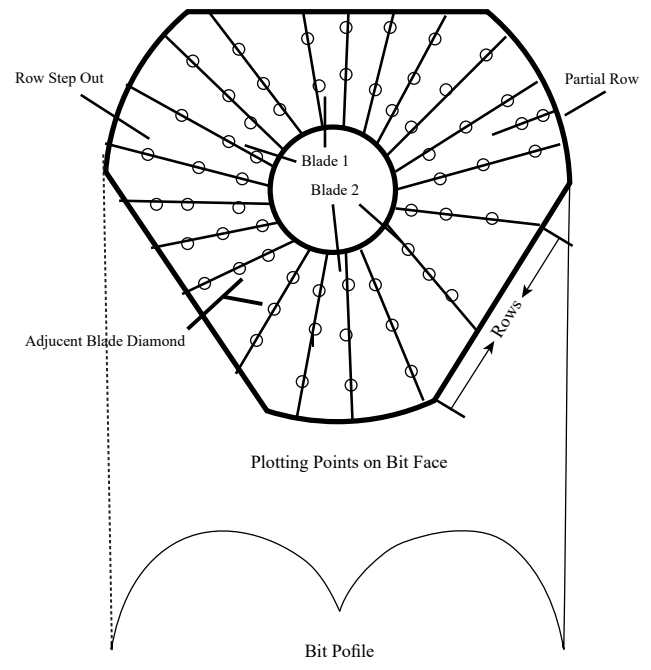

Fig. 9. Bit layout for a two-blade PDC bit (Peterson, 1976).
Eckel (1967) used the Reynolds number to calculate ROP as a function of mud properties. Chia and Smith (1986) developed a new nuzzle to increase the drilling hydraulics and ROP, consequently. They also developed a new equation to improve the prediction of ROP for this nuzzle and the relevant bits. Walker et al. (1986) developed a semi-analytical model for prediction of ROP by correlating it to several drilling parameters including WOB, well depth, in-situ compressive strength, porosity and average grain size. In addition, an alternative equation was developed for a specific case of Mohr-Coulomb circle not being available and consequently, compressive strength could not be determined. Later, Winters et al. (1987) proposed a model to correlate ROP with rock ductility and cone offset in RCB bits.

Caicedo et al. (2005) developed an ROP model which is mainly focused on bit properties and rock mechanical parameters. This model was derived based on the mechanical 
specific energy concept and it had the capability of being used for analyzing the real-time data. Later, Hareland et al. (2010) proposed a model focused on bit-rock interactions by considering the bit structure and its cutting mechanism. Several parameters like WOB, rotational speed and bit dullness rate are also considered in this model. This model has the capability to generate a rock failure model for prediction of UCS trends in RCB bits by using a row of bit inserts.

\subsubsection{The development of Bourgoyne and Young model and its modified versions}

Bourgoyne and Young (1974) proposed an equation for prediction of ROP in RCB bits. The effects of eight parameters on ROP are considered in this model but their interactions are ignored. In this model as a conventional and useful deterministic method for prediction of ROP, most of influencing parameters such as formation compaction and strength, pore pressure, WOB, rotational speed, bit hydraulics and also bit tooth wear are taken into account (Mammadov et al., 2015; Amer et al., 2017; Manshad et al., 2017). Maidla and Ohara (1991) added the effect of formation compressive strength to this model and Osgouei and Özbayoğlu (2007) modified it to cover more drilling parameters and conditions including well inclination, effective WOB, equivalent circulating density (ECD) and fluid loss effects, in order to attain a model wellsuited for directional and horizontal wells. Wiktorski et al. (2017) also improved and expanded the Bourgoyne and Young (1974) model by adding the "dogleg severity" and two more coefficients to consider the effects of well inclination and bit rotation, resulting in a noticeable improvement in prediction of ROP in horizontal and directional wells. They also developed a model for prediction of ROP for drilling with steerable mud motors.

\subsubsection{The development of Warren model and its modified versions}

Warren (1981) developed a two-part model for ROP prediction in soft formations based on operational conditions, bit type and formation properties. This model has the capability to predict ROP by correlating it to WOB, bit size and rock resistance, and ever since, it has been modified several times. Firstly, Warren (1987) expanded it to a three-part ROP model for RCB bits in which the effects of cutting production rate and the rate of cutting removal from the well were considered. Later on, Hareland and Hoberock (1993) added the effects of hole-cleaning problems, bit dullness rate and differential pressure to the original model in order to improve its performance and analyzing power. In addition, they introduced a wellbore cleaning function to model the profiles of "confined compressive strength" and "unconfined compressive strength" and also proposed an equation to convert these two types of strengths into each other. Afterwards, Hareland and Nygaard (2007) modified the Hareland and Hoberock (1993) model by correcting the rock mechanical parameters in this equation and expanding its application for different bits and lithology types. Table 3 shows a summary of analytical and semi-analytical ROP models developed specifically for RCB bits.

\subsection{Analytical and semi-analytical ROP models developed for PDC bits}

Although most of the previous ROP prediction studies have been focused on RCB bits so far, diamond bits are not neglected in this regard. In this way, Peterson (1976) proposed an analytical ROP model for these bits by focusing on the bit mechanical properties. Later, Wojtanowicz and Kuru (1987) developed another analytical model for PDC bits which is also focused on the physical properties of drilling bits, but more detailed and expanded.

Hareland and Rampersad (1994) developed a model for ROP calculation in natural diamond and PDC bits. Apart from the effects of main influential parameters, bit dullness rate and lithology properties are also considered in this model. Rastegar et al. (2008) modified this model to consider the equivalent bit radius, lithology coefficients, dynamic cutter action, and cutter wear (Hassan and Hussien, 2019). Shirkavand et al. (2009) modified the term of confined compressive strength in this equation in two different states of under-balanced drilling and conventional drilling. Later, Motahhari et al. (2010) developed an ROP model to consider the effects of positive displacement motors with PDC bits which was capable of predicting ROP from motor outputs.

Akbari et al. (2011) used the distinct element method for simulating the cutting process of PDC bits and developing an ROP model for these bits by focusing on bottomhole pressure. Later, Kerkar et al. (2014) proposed an ROP model for PDC bits based on the model of Hareland and Rampersad (1994), with considering the effects of rock mechanical properties, mud motor properties, bit mechanical properties, drilling hydraulics and drilling cuttings. Table 4 summarizes the characteristics of ROP models and correlations developed for diamond bits particularly.

\subsection{Empirical correlations developed for ROP prediction}

Several ROP correlations have been proposed in the literature throughout the history of ROP management. Firstly, Duklet and Bates (1980) expressed an empirical correlation for diamond bits by considering several fundamental drilling parameters including formation characteristics and bit design variables. In this correlation, bit rotational speed, hydraulic horsepower (HHP), fluid loss, average WOB (load per diamond per inch squared) and effective formations strength are chosen as the parameters affecting ROP. Later, Seifabad and Ehteshami (2013) developed an ROP correlation based on geological data. The parameters considered in this correlation are WOB, bit rotational speed, bit torque, mud weight, mud viscosity, bit condition and depth interval from the beginning to the end of drilling.

Bezminabadi et al. (2017) developed two correlations for prediction of ROP in different modes with or without considering rock mechanical properties. These correlations use WOB, bit rotational speed, mud flow rate and hole-depth, bit wear coefficient, friction angle, resistivity logs and neutron porosity hydrogen index as the parameters affecting ROP. Later, Alsubaih et al. (2018) used a linear regression analysis to generate 
Table 3. Analytical and semi-analytical ROP models developed for RCB bits.

\begin{tabular}{|c|c|}
\hline Researchers & Remarks \\
\hline Maurer (1962) & Covering both modes of perfect and imperfect hole-cleaning \\
\hline Galle and Woods (1963) & Controlled by two principal parameters (i.e., rotational speed and WOB) \\
\hline Mechem and Fullerton (1965) & Based on a specific drilling energy unit (i.e., WOB*N). \\
\hline Bingham (1964) & A modified version of Maurer model-Simple but not precise \\
\hline Eckel (1967) & Using Reynolds number to predict ROP based on mud properties \\
\hline Bourgoyne and Young (1974) & A strong and widely-used basis for prediction of ROP and pore pressure \\
\hline Warren (1981) & A two-part model specially for soft formations \\
\hline Chia and Smith (1986) & Developed for a specific type of nuzzles-Only applicable in tungsten carbide bits \\
\hline Walker et al. (1986) & Proposing an alternative equation for the case of not having the Mohr-Coulomb circle \\
\hline Warren (1987) & $\begin{array}{l}\text { A modified version of Warren (1981) model by adding the effects of cutting production rate and the rate of cutting } \\
\text { removal from the well }\end{array}$ \\
\hline Winters et al. (1987) & Developed based on Warren (1987) model-Correlating ROP with rock ductility and cone offset \\
\hline Maidla and Ohara (1991) & A modified version of Bourgoyne and Young (1974) model by adding the effect of formation compressive strength \\
\hline Hareland and Hoberock (1993) & $\begin{array}{l}\text { A modified version of Warren (1987) model by adding bit dullness rate, lithology properties, bit differential pressure } \\
\text { and the effects of hole-cleaning problems and creating the profiles of confined and unconfined compressive strengths } \\
\text { of the rock }\end{array}$ \\
\hline Caicedo et al. (2005) & $\begin{array}{l}\text { Developed based on the MSE concept-Focusing on bit properties and rock mechanical parameters-The capability of } \\
\text { analyzing the real-time drilling data }\end{array}$ \\
\hline Hareland and Nygaard (2007) & $\begin{array}{l}\text { A modified version of the Hareland and Hoberock (1993) model by correcting the rock mechanical parameters in this } \\
\text { equation }\end{array}$ \\
\hline Osgouei and Özbayoğlu (2007) & $\begin{array}{l}\text { A modified version of Bourgoyne and Young (1974) model-Proposing another model for determining the bit dullness } \\
\text { rate }\end{array}$ \\
\hline Hareland et al. (2010) & Focused on bit-rock interactions-Considering the bit structure and specially its cutting mechanism \\
\hline Wiktorski et al. (2017) & $\begin{array}{l}\text { A model for ROP prediction by using steerable mud motors-Improving the Bourgoyne and Young (1974) model by } \\
\text { adding the "dogleg severity" parameter-proper application for inclined wells }\end{array}$ \\
\hline
\end{tabular}

Table 4. Analytical and semi-analytical ROP models developed for PDC bits.

\begin{tabular}{ll}
\hline Researchers & Remarks \\
\hline Peterson (1976) & Strong analytical basis-Mainly focused on bit structure properties \\
Wojtanowicz and Kuru (1987) & Highly complicated because of high number of variables \\
Hareland and Rampersad (1994) & $\begin{array}{l}\text { Designed for natural diamond and also PDC bits-Considering the effects of bit dullness rate and lithology properties } \\
\text { Modifying the model of Hareland and Rampersad (1994) to consider the equivalent bit radius, lithology coefficients, } \\
\text { dynamic cutter action, and cutter wear } \\
\text { Rastegar et al. (2008) }\end{array}$ \\
Modifying the previous model of Hareland and Rampersad (1994) by developing an equation for calculation of \\
unconfined rock strength in both states of under-balanced and conventional drilling
\end{tabular}

several empirical correlations for prediction of ROP in different formations. These correlations were generated for shale and limestone formations separately and they correlate ROP to some of the affecting parameters including mud flow rate, bit rotational speed, mud weight and total flow area. Moreover,
Elkatatny (2019) proposed a correlation for ROP prediction by using an artificial neural network (ANN) which was optimized by self-adaptive differential evolution technique. The affecting parameters for developing this correlation were selected to be WOB, bit rotational speed, bit torque, UCS, hydraulic 
Table 5. Empirical Correlations developed for ROP prediction.

\begin{tabular}{|c|c|c|}
\hline Researchers & Remarks & Chosen variables \\
\hline Duklet and Bates (1980) & $\begin{array}{l}\text { Specially developed for diamond bits-Considering } \\
\text { formation characteristics and bit design variables }\end{array}$ & $\begin{array}{l}\text { Bit rotational speed, HHP, fluid loss, average WOB and } \\
\text { effective formation strength }\end{array}$ \\
\hline Seifabad and Ehteshami (2013) & $\begin{array}{l}\text { Considering geological data, mud properties and } \\
\text { operational drilling parameters }\end{array}$ & $\begin{array}{l}\text { WOB, bit rotational speed, depth, bit torque, mud density, } \\
\text { mud viscosity and bit condition (new or dull) }\end{array}$ \\
\hline Bezminabadi et al. (2017) & $\begin{array}{l}\text { Developed for two modes of with and without having } \\
\text { rock mechanical properties }\end{array}$ & $\begin{array}{l}\text { WOB, bit rotational speed, mud flow rate, depth, bit wear co- } \\
\text { efficient, friction angle, resistivity logs and hydrogen neutron } \\
\text { porosity index }\end{array}$ \\
\hline Alsubaih et al. (2018) & Generated for shale and limestone formations & $\begin{array}{l}\text { WOB, bit rotational speed, mud flow rate, bit torque, mud } \\
\text { density and total flow area. }\end{array}$ \\
\hline Elkatatny (2019) & $\begin{array}{l}\text { Developed by using a self-adaptive differential evo- } \\
\text { lution ANN }\end{array}$ & $\begin{array}{l}\text { WOB, bit rotational speed, bit torque, HHP, UCS, mud } \\
\text { viscosity and mud density }\end{array}$ \\
\hline Al-AbdulJabbar et al. (2019) & $\begin{array}{l}\text { Developed based on drilling parameters and mud } \\
\text { properties, by using non-linear regression analysis }\end{array}$ & $\begin{array}{l}\text { WOB, bit rotational speed, mud flow rate, bit torque, UCS, } \\
\text { standpipe pressure, mud viscosity and mud density }\end{array}$ \\
\hline Al-AbdulJabbar et al. (2020) & $\begin{array}{l}\text { Developed based on drilling parameters and conven- } \\
\text { tional well logs, by using a self-adaptive differential } \\
\text { evolution ANN }\end{array}$ & $\begin{array}{l}\text { Bit rotational speed, bit toque, WOB, gamma-ray and forma- } \\
\text { tion bulk density }\end{array}$ \\
\hline
\end{tabular}

horsepower, mud density and mud viscosity.

Al-AbdulJabbar et al. (2019) developed an empirical ROP model for carbonate formations based on several drilling parameters (i.e., WOB, UCS, mud flow rate, bit torque and standpipe pressure) and also mud properties (i.e., viscosity and density) by using the non-linear regression analysis for determining the unknown coefficients of the model. Later, Al-AbdulJabbar et al. (2020) developed another correlation by using an optimized ANN for prediction of ROP. This correlation was developed for horizontal drilling of carbonate reservoirs as a function of drilling parameters such as rotational speed, bit torque and WOB, combined with conventional well logs including gamma ray, deep resistivity and formation bulk density.

Table 5 details the information about the ROP correlations developed for ROP prediction and summarizes their characteristics. Based on this table, it is readily apparent that WOB (or average WOB) and bit rotational speed have been selected as the influencing parameters in all correlations. After these two parameters, bit torque (5 times), mud density (4 times), formation strength (3 times), mud viscosity (3 times) and mud flow rate (3 times) are the most repeated parameters in this regard. It seems that using these parameters for developing an ROP correlation is almost necessary; however, other related parameters such as bit wear condition (2 times), HHP (2 times) and hole depth (2 times) are not neglected in previous ROP correlations.

\subsection{ROP models developed for horizontal and deviated wells}

Drilling in horizontal and deviated wells is becoming more and more widespread and the need for drilling optimization process in these wells is being felt more than ever (Osgouei and Özbayoğlu, 2007). So far, most of the ROP management studies are performed in vertical wells, while performing such process in horizontal and deviated wells is more necessary due to special mechanisms of hole-cleaning in these wells
(Cho et al., 2002; Busahmin et al., 2017; Najjarpour et al., 2020). During directional and horizontal well drilling, many additional challenges such as limited WOB, excessive torque and drag, harder hole-cleaning and difficult trajectory control occur compared with vertical wells (Osgouei and Özbayoğlu, 2007; Najjarpour et al., 2020). In this section, several ROP models are reviewed which have special applications in horizontal and deviated wells.

Among all of the analytical, semi-analytical and empirical ROP models, four models (Osgouei and Özbayoğlu, 2007; Kerkar et al., 2014; Wiktorski et al., 2017; Etesami et al., 2021) are recognized to be highly-applicable for horizontal and directional wells, because of special features incorporated in these models. It should be noted that the ROP models of Kerkar et al. (2014) and Etesami et al. (2021) are developed for PDC bits while the models of Osgouei and Özbayoğlu (2007) and Wiktorski et al. (2017) are known to be the modified versions of Bourgoyne and Young (1974) model tuned for drilling with RCB bits in horizontal and directional wells.

Osgouei and Özbayoğlu (2007) added the effects of well inclination to the original model of Bourgoyne and Young (1974) by defining an extra variable for this purpose. Later, Wiktorski et al. (2017) expanded the Bourgoyne and Young (1974) model by adding the "dogleg severity" parameter to consider the effects of well inclination. These two ROP models have shown proper performances in horizontal and directional wells, but a performance comparison between these models is suggested for future studies.

Kerkar et al. (2014) proposed a methodology for ROP prediction with PDC bits (especially in horizontal and deviated wells) by calculating the wellbore friction force, adjusting the hook-load, computing friction coefficient and estimating downhole WOB by applying a standpipe pressure correction to the calculated hook-load and considering potential abrasiveness and sliding. Later on, Etesami (2021) presented a semianalytical ROP model for PDC bits based on the conventional model of Bourgoyne and Young (1974) which should be 


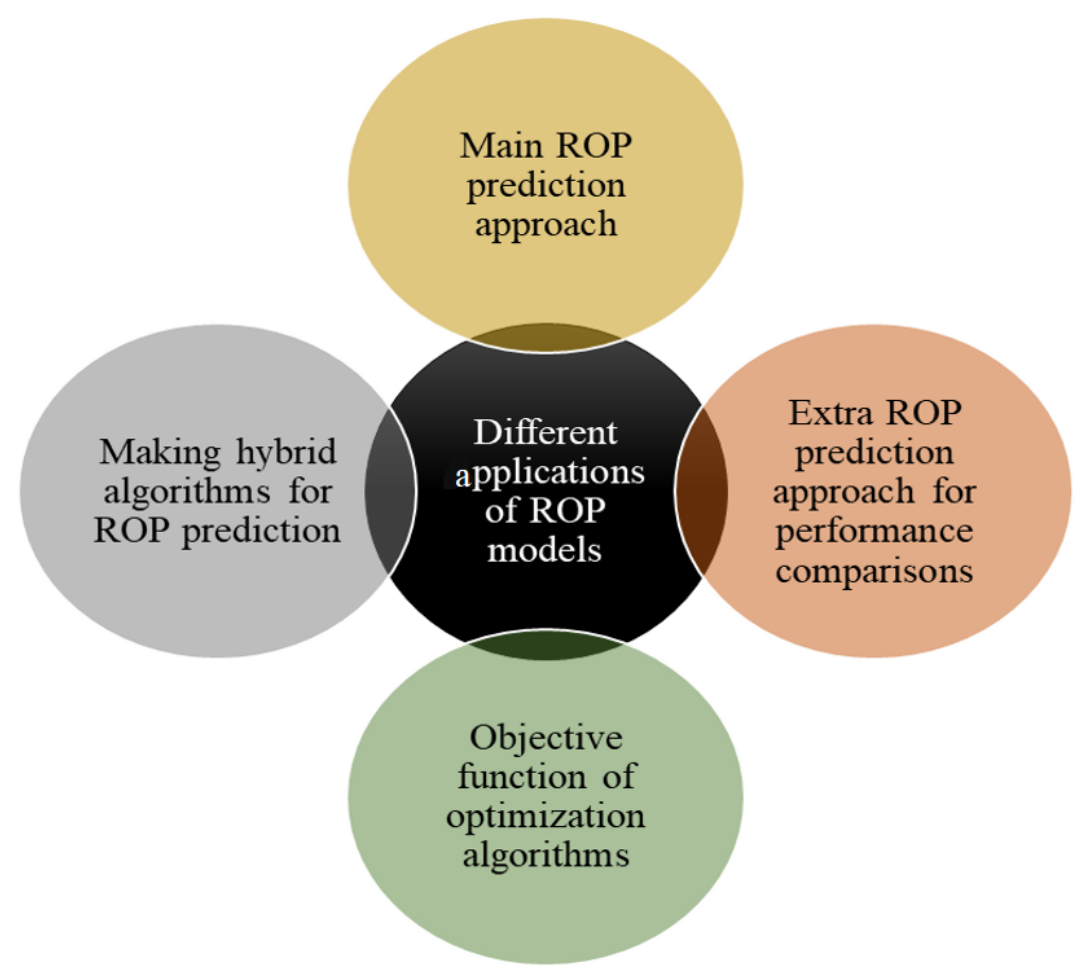

Fig. 10. Different applications of ROP models.

tuned based on formations. This model is highly applicable in inclined wells as it incorporates several pivotal parameters such as ECD, downhole motor, mechanical WOB, inclination, equilibrium cuttings bed thickness and downhole cuttings concentration, making it a good candidate for prediction of ROP in horizontal and deviated wells located in offshore gas fields. Multiple regression method should be used to adjust the coefficients of the model; however, a functional algorithm was introduced for better calculation of the unknown parameters and coefficients of this model based on formations.

\section{Field applications and performance comparison studies for ROP management}

It should be noted that the main purpose of developing analytical and semi-analytical models is to use them for field applications. While several studies have used analytical and semi-analytical ROP models as the basic method for ROP prediction, others have chosen ROP models as the objective functions for different optimization algorithms or as extra ROP prediction methods to use their results for performance comparison purposes (Barbosa et al., 2019). Making hybrid algorithms for ROP prediction by using pre-existing models is another function of these models implemented in the literature (Hegde et al., 2018; Najjarpour et al., 2020). Different applications of ROP models are depicted in Fig. 10, in which the types of ROP models are not distinguished. In the following sub-sections, a group of studies which have used the analytical and semi-analytical ROP models and empirical correlations for ROP management are reviewed to highlight the importance and effectivity of these models.

\subsection{Analytical, semi-analytical and empirical ROP models as the main approach}

Al-Betairi et al. (1988) studied the application of Bourgoyne and Young (1974) model in several oil wells. They observed some problems in using the multiple regression method for determining the coefficients of this model; therefore, they concluded that this approach is only valid for homogenous formations. Rampersad et al. (1994) used two models of Hareland and Hoberock (1993) and Hareland and Rampersad (1994) to evaluate their performances in drilling with RCB and PDC bits and compared their results with the results of geological drilling logs. Bahari and Baradaran Seyed (2007a, 2007b) compared four methods to determine the coefficients of Bourgoyne and Young (1974) model for ROP management in Khangiran gas field, in Northeast of Iran. As a result of this study, "trust-region" method was recognized to be the best. Further investigations, however, revealed that this method can be outperformed by other mathematical (i.e., progressive stochastic method) and artificial intelligence methods (i.e., genetic algorithm) for determining the unknown coefficients of Bourgoyne and Young (1974) model (Bahari et al., 2011; Rahimzadeh et al., 2011). For more information about these methods, studying several sources are proposed; as such, for trust-region (Sorensen, 1981; Moré and Sorensen, 1983; Conn et al., 2000), for progressive stochastic method (Rahimzadeh et al., 2011; Xiao and Zhang, 2014) and for GA (Holland, 1992; Whitley, 1994; Eberhart and Shi, 1998; Najjarpour and Jalalifar, 2018; Rahmanifard and Plaksina, 2018) can be mentioned.

Nygaard and Hareland (2007) proposed a model to estimate 
the drilling time and bit wear by using the rock strength. For testing this method and their own ROP model (Hareland and Nygaard, 2007), they performed two ROP management studies in North Sea; which confirmed the effectiveness of this methodology. Later, Rastegar et al. (2008) developed an ROP simulator based on modified Warren model and also proposed some drilling instructions to increase ROP. Moreover, Bataei et al. (2010) compared the performance of three different ROP models including Bingham (1964), Bourgoyne and Young (1974), and Warren (1987) to find the best model based on formation types and predict the values of ROP by using the superior model. They developed an ROP management program including some instructions about drilling in each formation with optimum ROP and also optimum values of influencing parameters.

Mostofi et al. (2010) used mud logging data from an Iranian oil field to simulate an ROP model for that field based on the modified Warren model. Eren and Özbayoğlu (2010) used the Bourgoyne and Young (1974) model for ROP prediction by applying the statistical approach of multiple regressions for determining the unknown parameters of this model. Rahimzadeh et al. (2010) compared the performance of Bourgoyne and Young (1974) and Warren (1987) models in one of the gas fields of Persian Gulf. Later, they proposed the use of progressive stochastic method as a new methodology for determining the coefficients of Bourgoyne and Young (1974) model, resulting in a better performance than the trust-region and multiple regression methods (Rahimzadeh et al., 2011).

Sui et al. (2013) used a predictive approach to optimize the Bourgoyne and Young (1974) model for prediction of ROP in a well located in North Sea. During this study, application of Kalman filter was tested for estimating a statistical optimal state on noisy input data. Later on, Nascimento et al. (2015) and Kutas et al. (2015) investigated the applicability of Bourgoyne and Young (1974) model in Presalt formations of Atlantic Ocean, close to the shores of Brazil and Angola. Formighieri and Freitas (2015) used another methodology (i.e., Markov Chain Monte Carlo Simulation) to obtain the model coefficients of Bourgoyne and Young (1974) model to use it for prediction of ROP in three offshore wells. In this method, instead of determining fixed values for the model coefficients, creating probabilistic distributions for these parameters were replaced which improved the performance of this ROP model significantly.

Soares et al. (2016) conducted a performance comparison study in Williston Basin, located in North Dakota. They compared the performance of three ROP models including Bingham (1964), Hareland and Rampersad (1994) and Motahhari et al. (2010) in several formations. Later, Hazem Hassan and Abdul Hossein (2019) used the ROP model of Rastegar et al (2008), as a modification of Hareland and Hoberock (1994) model, for optimization of ROP. The procedure executed by utilizing the real time data from Buzargan oil field in Iraq.

Hegde et al. (2019) included the effects of drilling vibrations in ROP management by using a random forest $(\mathrm{RF})$ classifier algorithm to predict the vibrations and setting vibration constrains for the tolerance of controllable parameters affecting ROP. During this study, several analytical ROP models were used for prediction of ROP and as a result, the model of Hareland and Hoberock (1993) expressed the highest accuracy. Therefore, it was chosen as the main objective function to be optimized by the gradient ascent algorithm with random restarts. This study showed that a combination of using analytical ROP models with mathematical approaches along with machine learning algorithms will be useful and effective in both aspects of ROP prediction and optimization.

Besides of the studies which have used the analytical and semi-analytical ROP models for the purpose of ROP management, lots of studies used their own ROP models for ROP management to test their applications (Galle and Woods, 1963; Eckel, 1967; Bourgoyne and Young, 1974; Peterson, 1976; Duklet and Bates, 1980; Warren, 1981, 1987; Chia and Smith, 1986; Walker et al., 1986; Winters et al., 1987; Wojtanowicz and Kuru, 1987; Maidla and Ohara, 1991; Hareland and Hoberock, 1993; Hareland and Rampersad, 1994; Caicedo et al., 2005; Hareland and Nygaard, 2007; Osgouei and Özbayoğlu, 2007; Shirkavand et al., 2009; Hareland et al., 2010; Motahhari et al., 2010; Seifabad and Ehteshami, 2013; Kerkar et al., 2014; Bezminabadi et al., 2017; Wiktorski et al., 2017; Al-AbdulJabbar et al., 2019; Elkatatny, 2019; AlAbdulJabbar et al., 2020; Etesami et al., 2021). Table 6 shows a brief review on research studies which have used different ROP models and empirical correlations as the main approach for ROP management.

\subsection{Analytical, semi-analytical and empirical ROP models as an extra method}

As mentioned before, the purpose of this study is to review the performance comparison studies and field applications by using the analytical, semi-analytical and empirical ROP models as the main approach for ROP management. However, these methods have also been used in some of the previous studies as an extra method for ROP prediction or as the objective function in the ROP optimization algorithms. Most of these studies have already been reviewed by Barbosa et al. (2019), while Table 7 summarizes those reviewed in this study.

As reported in Table 7, Bourgoyne and Young (1974) model has been used as an extra ROP management method for comparing with the results of other ROP prediction methods more repeatedly (19 times), while Bingham (1963) model (9 times) and Hareland and Rampersad (1994) model (4 times) stand in the next places. Almost all of these studies have selected the artificial intelligence algorithms as the main approach for ROP management. In this way, ANNs (11 times), ensemble machine learning algorithms (6 times), and adaptive neuro-fuzzy inference system (ANFIS) (4 times) have been repeated more than other approaches of ROP management, respectively. Moreover, the ROP model of Hareland and Hoberock (1993), as a modified version of Warren (1987) model, has been successfully implemented (twice) as the whole or a part of the objective function for different optimization algorithms. 
Table 6. ROP management studies by using analytical, semi-analytical and empirical ROP models as the main approach for ROP prediction.

\begin{tabular}{|c|c|c|c|}
\hline Researchers & ROP Model & Region & Results \\
\hline Galle and Woods (1963) & Galle and Woods (1963) & USA & 7 to 44 percent cost reduction in drilling \\
\hline Eckel (1965) & Eckel (1965) & USA & ROP improvement by decreasing the kinematic viscosity \\
\hline Bourgoyne and Young (1974) & Bourgoyne and Young (1974) & USA (Gulf Coast) & 10 to 80 percent cost reduction in drilling \\
\hline Peterson (1976) & Peterson (1976) & USA (Uintah Basin) & $25 \%$ ROP improvement \\
\hline Duklet and Bates (1980) & Duklet and Bates (1980) & $\begin{array}{l}\text { USA } \\
\text { (Louisiana and Utah) }\end{array}$ & $\begin{array}{l}\text { Average relative error of } 15.3 \% \text { and maximum relative } \\
\text { error of } 40.5 \% \text { for ROP prediction }\end{array}$ \\
\hline Warren (1981) & Warren (1981) & USA (Catoosa shale) & Average relative error of $14.5 \%$ in ROP prediction \\
\hline Chia and Smith (1986) & Chia and Smith (1986) & USA (Texas) & $\begin{array}{l}18 \% \text { ROP improvement by using the designed mini- } \\
\text { extended nuzzles }\end{array}$ \\
\hline Walker et al. (1986) & Walker et al. (1986) & USA & Correlation factor of 0.88 and 0.9 for ROP prediction \\
\hline Wojtanowicz and Kuru (1987) & Wojtanowicz and Kuru (1987) & USA (Gulf Coast) & Cost reduction of 30 to 300 percent \\
\hline Warren (1987) & Warren (1987) & $\begin{array}{l}\text { USA } \\
\text { (Indiana and } \\
\text { Carthage limestone) }\end{array}$ & Proper accuracy of ROP prediction in both formations \\
\hline Winters et al. (1987) & Winters et al. (1987) & $\begin{array}{l}\text { USA } \\
\text { (Catoosa shale and } \\
\text { Carthage limestone) }\end{array}$ & $\begin{array}{l}\text { A range of } 0.4 \text { to } 2 \text { percent mean square error for ROP } \\
\text { prediction in different wells }\end{array}$ \\
\hline Al-Betairi et al. (1988) & Bourgoyne and Young (1974) & Saudi Arabia & $\begin{array}{l}\text { Inefficiency of multiple regression in heterogeneous } \\
\text { formations }\end{array}$ \\
\hline Maidla and Ohara (1991) & Maidla and Ohara (1991) & $\begin{array}{l}\text { Brazil } \\
\text { (Alagaos field) }\end{array}$ & $\begin{array}{l}\text { Better ROP prediction than the original model of } \\
\text { Bourgoyne and Young (1974) }\end{array}$ \\
\hline Hareland and Hoberock (1993) & Hareland and Hoberock (1993) & $\begin{array}{l}\text { USA } \\
\text { (Texas and Wyoming) }\end{array}$ & $\begin{array}{l}\text { Better ROP prediction than the original model of Warren } \\
\text { (1987) }\end{array}$ \\
\hline $\begin{array}{l}\text { Hareland and Rampersad } \\
\text { (1994) }\end{array}$ & $\begin{array}{l}\text { Hareland and Rampersad } \\
\text { (1994) }\end{array}$ & $\begin{array}{l}\text { USA } \\
\text { (Catoosa shale and } \\
\text { Carthage limestone) }\end{array}$ & Proper accuracy of ROP prediction in both formations \\
\hline Rampersad et al. (1994) & $\begin{array}{l}\text { Hareland and Hoberock (1993) } \\
\text { Hareland and Rampersad (1994) }\end{array}$ & USA (East Texas) & Cost reduction of $75 \%$ \\
\hline Caicedo et al. (2005) & Caicedo et al. (2005) & USA & $\begin{array}{l}\text { Proper accuracy of ROP prediction and providing a } \\
\text { platform for optimization of ROP }\end{array}$ \\
\hline $\begin{array}{l}\text { Bahari and Baradaran Seyed } \\
(2007 a, 2007 b)\end{array}$ & Bourgoyne and Young (1974) & $\begin{array}{l}\text { Iran } \\
\text { (Khangiran gas field) }\end{array}$ & Cost reduction of 30 to 180 percent \\
\hline Hareland and Nygaard (2007) & Hareland and Nygaard (2007) & Norway (North Sea) & Proper accuracy of ROP prediction \\
\hline Nygaard and Hareland (2007) & Hareland and Nygaard (2007) & Norway (North Sea) & Proper accuracy of ROP prediction \\
\hline Osguei and Özbayoğlu (2007) & Osguei and Özbayoğlu (2007) & $\begin{array}{l}\text { Iran } \\
\text { (Persian Gulf) }\end{array}$ & $\begin{array}{l}\text { Better ROP prediction than the original model of } \\
\text { Bourgoyne and Young (1974) in horizontal and } \\
\text { directional wells }\end{array}$ \\
\hline Rastegar et al. (2008) & Rastegar et al. (2008) & $\begin{array}{l}\text { Iran } \\
\text { (Salman oil field) }\end{array}$ & $\begin{array}{l}\text { Functionality of the model for ROP prediction in spite of } \\
\text { its simplicity }\end{array}$ \\
\hline Shirkavand et al. (2009) & Shirkavand et al. (2009) & Iran & $\begin{array}{l}\text { Proper accuracy of ROP prediction for under balanced } \\
\text { drilling }\end{array}$ \\
\hline Bataei et al. (2010) & $\begin{array}{l}\text { Bingham (1964) } \\
\text { Bourgoyne and Young (1974) } \\
\text { Warren (1987) }\end{array}$ & $\begin{array}{l}\text { Iran } \\
\text { (Shadegan oil field) }\end{array}$ & $\begin{array}{l}\text { Prediction of ROP by the optimum model for each } \\
\text { formation }\end{array}$ \\
\hline Motahhari et al. (2010) & Motahhari et al. (2010) & Canada (Alberta) & Proper performance in ROP prediction \\
\hline Hareland et al. (2010) & Hareland et al. (2010) & Canada & Proper accuracy in prediction of ROP and rock strength \\
\hline Mostofi et al. (2010) & Hareland and Hoberock (1993) & $\begin{array}{l}\text { Iran } \\
\text { (Asmari formation) }\end{array}$ & Cost reduction of 38 percent on average \\
\hline Eren and Özbayoğlu (2010) & Bourgoyne and Young (1974) & Iran (Persian Gulf) & Proper ROP prediction accuracy \\
\hline Rahimzadeh et al. (2010) & $\begin{array}{l}\text { Bourgoyne and Young (1974) } \\
\text { Warren (1987) }\end{array}$ & Iran (Persian Gulf) & $\begin{array}{l}\text { Preference of Bourgoyne and Young (1974) model with } \\
\text { the correlation factor of } 0.812\end{array}$ \\
\hline Rahimzadeh et al. (2011) & Bourgoyne and Young (1974) & Iran (Persian Gulf) & $\begin{array}{l}4.4 \text { to } 6.3 \text { percent average error for ROP prediction by } \\
\text { using the progressive stochastic method for determining } \\
\text { the model coefficients }\end{array}$ \\
\hline $\begin{array}{l}\text { Seifabad and Ehteshami } \\
\text { (2013) }\end{array}$ & $\begin{array}{l}\text { Seifabad and Ehteshami } \\
(2013)\end{array}$ & Iran (Ahvaz Field) & 67.2 to 85.7 percent accuracy in different formations \\
\hline
\end{tabular}


Table 6. ROP management studies by using analytical, semi-analytical and empirical ROP models as the main approach for ROP prediction. (Continued)

\begin{tabular}{|c|c|c|c|}
\hline Researchers & ROP Model & Region & Results \\
\hline Sui et al. (2013) & Bourgoyne and Young (1974) & Norway (North Sea) & $\begin{array}{l}\text { Applicability of model predictive control strategy in } \\
\text { improving the ROP prediction accuracy }\end{array}$ \\
\hline Kerkar et al. (2014) & Kerkar et al. (2014) & Canada (Alberta) & Proper accuracy of ROP prediction \\
\hline Formighieri and Freitas (2015) & Bourgoyne and Young (1974) & Brazil & 0.03 to 0.09 mean absolute percentage error \\
\hline Kutas et al. (2015) & Bourgoyne and Young (1974) & $\begin{array}{l}\text { Brazil (Santos and } \\
\text { Campos basins) }\end{array}$ & $26.6 \%$ relative error \\
\hline Nascimento et al. (2015) & Bourgoyne and Young (1974) & $\begin{array}{l}\text { Brazil (Santos and } \\
\text { Campos basins) }\end{array}$ & $27 \%$ relative error \\
\hline Soares et al. (2016) & $\begin{array}{l}\text { Bingham (1964) } \\
\text { Hareland and Rampersad (1994) } \\
\text { Motahhari et al. (2010) }\end{array}$ & $\begin{array}{l}\text { USA } \\
\text { (Williston Basin, } \\
\text { North Dakota) }\end{array}$ & $\begin{array}{l}\text { Superiority of Hareland and Rampersad (1994) model } \\
\text { with a range of } 20 \text { to } 25 \text { percent relative error in different } \\
\text { formations }\end{array}$ \\
\hline Wiktorski et al. (2017) & Wiktorski et al. (2017) & Norway & $\begin{array}{l}\text { Better ROP prediction than the original model of } \\
\text { Bourgoyne and Young (1974) }\end{array}$ \\
\hline Bezminabadi et al. (2017) & Bezminabadi et al. (2017) & $\begin{array}{l}\text { Iran } \\
\text { (Azadegan oil field) }\end{array}$ & Correlation factor of 0.62 in ROP prediction \\
\hline Al-AbdulJabbar et al. (2019) & Al-AbdulJabbar et al. (2019) & Saudi Arabia & $\begin{array}{l}\text { Average absolute error of } 5 \% \text { and correlation factor of } \\
0.93\end{array}$ \\
\hline $\begin{array}{l}\text { Hazem Hassan and } \\
\text { Abdul Hussein (2019) }\end{array}$ & Rastegar et al. (2008) & $\begin{array}{l}\text { Iraq } \\
\text { (Buzargan oil field) }\end{array}$ & $94 \%$ accuracy of ROP prediction \\
\hline Elkatatny (2019) & Elkatatny (2019) & Saudi Arabia & $\begin{array}{l}\text { Correlation factor of } 0.98 \text { and } 5 \% \text { average absolute } \\
\text { percentage error }\end{array}$ \\
\hline Hegde et al. (2019) & $\begin{array}{l}\text { Bingham (1964) } \\
\text { Bourgoyne and Young (1974) } \\
\text { Hareland and Hoberock (1993) } \\
\text { Motahhari et al. (2010) }\end{array}$ & $\begin{array}{l}\text { USA } \\
\text { (Williston Basin, } \\
\text { North Dakota) }\end{array}$ & $\begin{array}{l}\text { Superiority of Hareland and Hoberock (1993) model } \\
\text { in ROP prediction with } 14 \% \text { average normalized error } \\
\text { and } 14.1 \% \text { ROP improvement as the result of ROP } \\
\text { optimization }\end{array}$ \\
\hline Al-AbdulJabbar et al. (2020) & Al-AbdulJabbar et al. (2020) & Saudi Arabia & $\begin{array}{l}\text { Correlation factor of } 0.956 \text { and } 5.29 \% \text { average absolute } \\
\text { percentage error }\end{array}$ \\
\hline Etesami et al. (2021) & Etesami et al. (2021) & Canada & Correlation factor of 0.81 to 0.96 in different wells \\
\hline
\end{tabular}

\section{Discussion}

Having reviewed the ROP management projects and studies by using the analytical and semi-analytical models, it can be inferred that the Bourgoyne and Young (1974) model has been used as the main ROP model for field managements more than others. The results of this study confirms that no other ROP model can outnumber this one in field management applications, which is stated in previous studies as well (Mammadov et al., 2015). It is not a wonder that Bourgoyne and Young (1974) model has been used more than other ROP models; because it is known as the most famous and widely-accepted model for prediction of ROP in field management studies (Mammadov et al., 2015; Amer et al., 2017; Manshad et al., 2017). Our analysis also shows that the model of Hareland and Hoberock (1993) (the modified Warren model) stands in the second place of the most repeated ROP models in field management applications.

By focusing on Table 2, it can be seen that several ROP models are actually modified versions of the previous well-known models, such as Warren (1987) and Bourgoyne and Young (1974); therefore, it is better to cumulate these models in single categories. Fig. 11 shows the shares of these categories being used as the main approach for ROP management projects and studies. In this figure, the models of Warren (1987) and Bourgoyne and Young (1974) and also all the modified versions of these models are categorized in two separate groups, while the rest of ROP models developed for RCB bits are put in another category. Besides, analytical and semi-analytical ROP models developed for PDC bits and also empirical correlations are cumulated in other categories.

As it can be seen in Fig. 11, Bourgoyne and Young (1974) model and its modified versions outnumber the category of Warren (1987) model and its modified versions. In fact, proper performance of the original Bourgoyne and Young (1974) model has made this ROP model as a good candidate for performing ROP management projects, while the simplicity and affectivity of Warren (1974) model has persuaded several authors to develop new modified ROP models based on this model and use them for field management applications. This model (or its modified versions) has been used as a practical method or as the objective function of artificial intelligence algorithms in the literature (Elahifar et al., 2012; Yi et al., 2015; Jiang and Samuel, 2016), as well.

Table 6 highlights the results of reviewed studies in terms of precision of ROP prediction, the amount of ROP improvement and the reduction of drilling costs, which confirms the proper applicability of analytical and semi-analytical ROP models in field management studies. Besides of these results, a summary of important findings of the reviewed studies is listed in this table. According to this table, Bourgoyne and 
Table 7. Research studies by using analytical, semi-analytical and empirical ROP models as an extra approach for ROP management or the objective function of optimization algorithms.

\begin{tabular}{|c|c|c|}
\hline Researchers & Chosen ROP Models & Main ROP Management Approach \\
\hline Moradi et al. (2010) & $\begin{array}{l}\text { Bourgoyne and Young (1974) } \\
\text { (optimized by genetic algorithm) }\end{array}$ & Artificial intelligence algorithms (hybrid Fuzzy Logic) \\
\hline Arabjamaloei and Shadizadeh (2011) & Bourgoyne and Young (1974) & Artificial intelligence algorithms (ANN) \\
\hline Bahari et al. (2011) & $\begin{array}{l}\text { Bourgoyne and Young (1974) } \\
\text { [optimized by genetic algorithm } \\
\text { and trust-region method] }\end{array}$ & $\begin{array}{l}\text { Artificial intelligence algorithms (General Regression Neural } \\
\text { Network) }\end{array}$ \\
\hline Amar and Ibrahim (2012) & Bourgoyne and Young (1974) & Artificial intelligence algorithms (ANN) \\
\hline AlArfaj et al. (2012) & Bourgoyne and Young (1974) & Artificial intelligence algorithms (ANN) \\
\hline Arabjamaloei and Karimi Dehkordi (2012) & $\begin{array}{l}\text { Bourgoyne and Young (1974) } \\
\text { Hareland and Hoberock (1993) }\end{array}$ & Artificial intelligence algorithms (ANN, ANFIS) \\
\hline Bataee et al. (2014) & $\begin{array}{l}\text { Bingham (1964) } \\
\text { Bourgoyne and Young (1974) } \\
\text { Warren (1987) }\end{array}$ & Artificial intelligence algorithms (ANN) \\
\hline Guria et al. (2014) & Bourgoyne and Young (1974) & $\begin{array}{l}\text { Artificial intelligence algorithms (elitist non-dominated sorting } \\
\text { algorithm) }\end{array}$ \\
\hline Awatonde and Mutasiem (2014) & Hareland and Hoberock (1993)* & $\begin{array}{l}\text { Artificial intelligence algorithms (Differential Evolution } \\
\text { Algorithm) }\end{array}$ \\
\hline Jiang and Samuel (2016) & Hareland and Hoberock (1993)* & $\begin{array}{l}\text { Artificial intelligence algorithms (ANN, Ant Colony Opti- } \\
\text { mization) }\end{array}$ \\
\hline Khosravanian et al. (2016) & Bourgoyne and Young (1974) & Artificial intelligence algorithms (Fuzzy Logic) \\
\hline Hegde et al. (2017) & $\begin{array}{l}\text { Bingham (1964) } \\
\text { Motahhari et al. (2010) } \\
\text { Hareland and Rampersad (1994) }\end{array}$ & $\begin{array}{l}\text { Artificial intelligence algorithms (Ensemble Machine } \\
\text { Learning Algorithms) }\end{array}$ \\
\hline Hegde and Gray (2017) & $\begin{array}{l}\text { Bingham (1964) } \\
\text { Motahhari et al. (2010) } \\
\text { Hareland and Rampersad (1994) }\end{array}$ & $\begin{array}{l}\text { Artificial intelligence algorithms (Ensemble Machine } \\
\text { Learning Algorithms) }\end{array}$ \\
\hline Tewari and Dewivedi (2017) & Bourgoyne and Young (1974) & Artificial intelligence algorithms (ANN) \\
\hline Ayoub et al. (2017) & $\begin{array}{l}\text { Bingham (1964) } \\
\text { Bourgoyne and Young (1974) }\end{array}$ & Artificial intelligence algorithms (ANFIS) \\
\hline Elkatatny (2018) & $\begin{array}{l}\text { Maurer (1963) } \\
\text { Bingham (1964) } \\
\text { Bourgoyne and Young (1974) }\end{array}$ & Artificial intelligence algorithms (ANN) \\
\hline Diaz et al. (2018) & Bourgoyne and Young (1974) & Artificial intelligence algorithms (ANN) \\
\hline Yavari et al. (2018) & $\begin{array}{l}\text { Bourgoyne and Young (1974) } \\
\text { Hareland and Rampersad (1994) }\end{array}$ & Artificial intelligence algorithms (ANFIS) \\
\hline Alsubaih et al. (2018) & $\begin{array}{l}\text { Bourgoyne and Young (1974) } \\
\text { Alsubaih et al. (2018) }\end{array}$ & Mechanical specific energy concept \\
\hline Hadi et al. (2019) & Bourgoyne and Young (1974) & Artificial intelligence algorithms (ANN) \\
\hline Soares and Gray (2019) & $\begin{array}{l}\text { Bingham (1964) } \\
\text { Bourgoyne and Young (1974) } \\
\text { Hareland and Rampersad (1994) } \\
\text { Motahhari et al. (2010) }\end{array}$ & $\begin{array}{l}\text { Artificial intelligence algorithms (Ensemble Machine } \\
\text { Learning Algorithms) }\end{array}$ \\
\hline Ahmed et al. (2019) & $\begin{array}{l}\text { Maurer (1963) } \\
\text { Bingham (1963) }\end{array}$ & Artificial intelligence algorithms (Fuzzy Logic) \\
\hline Najjarpour et al. (2020) & $\begin{array}{l}\text { Bingham (1963) [Optimized by } \\
\text { trust-region method] } \\
\text { Bezminabadi et al. (2017) }\end{array}$ & $\begin{array}{l}\text { Artificial intelligence algorithms (Ensemble Machine } \\
\text { Learning Algorithms) }\end{array}$ \\
\hline Elkatatny (2020); Elkatatny et al. (2020) & $\begin{array}{l}\text { Maurer (1963) } \\
\text { Bingham (1963) } \\
\text { Bourgoyne and Young (1974) }\end{array}$ & $\begin{array}{l}\text { Artificial intelligence algorithms (ANN, Ensemble Machine } \\
\text { Learning Algorithms, ANFIS) }\end{array}$ \\
\hline Kor and Altun (2020) & Bourgoyne and Young (1974) & $\begin{array}{l}\text { Artificial intelligence algorithms (Ensemble Machine } \\
\text { Learning Algorithms) }\end{array}$ \\
\hline
\end{tabular}




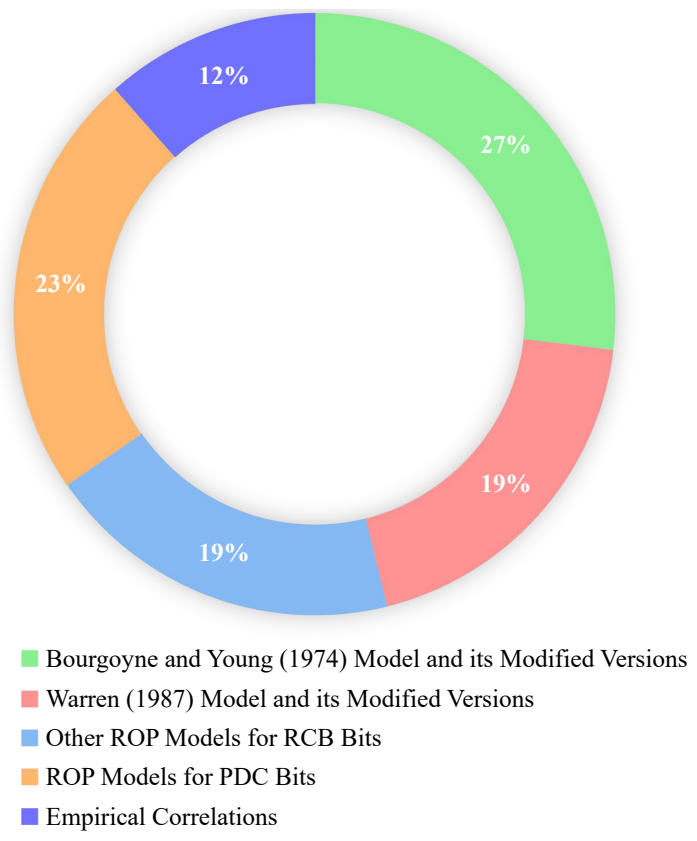

Fig. 11. Proportion of different ROP models being used as the main approach for ROP management.

Young (1974) model (or its modified versions) is thought to be the most precise ROP model, by showing proper ROP prediction performances in almost all cases, while Elkatatny (2019) correlation has recorded the most precision among all the listed ROP correlations. Still, for better comparison of these methods, using a uniform dataset and possible readjustment of these correlations are needed which can be a subject to be evaluated in future performance comparison studies.

Based on the previous findings (Bahari and Baradaran Seyed, 2007b), the trust-region algorithm is a valid option for finding unknown coefficients of the Bourgoyne and Young (1974) model; however, this method has been outperformed by progressive stochastic method (Rahimzadeh et al., 2011) and also genetic algorithm (Bahari et al., 2011). Therefore, application of the Bourgoyne and Young (1974) model with one of these methods is a proper suggestion for future field applications, if using analytical, semi-analytical and empirical ROP models are supposed to be the main approach for ROP management. This approach was tested in previous studies (Bahari and Baradaran Seyed, 2007a; Bahari et al., 2011; Rahimzadeh et al., 2011; Soares and Gray, 2019) and promising results achieved.

By focusing on Table 7, it is apparent that Bourgoyne and Young (1974) model has proved its application in ROP prediction as an extra ROP management approach for adopting performance comparison (mostly with ANN models) in a majority of the studies, while Bingham (1963) and Hareland and Rampersad (1994) models rank in the next places. Moreover, by focusing on the performance of Hareland and Hoberock (1993) model (modified Warren model) in this table, it is persuasive to consider it as a proper choice for the objective function of optimization algorithms in ROP management studies due to its simplicity and accuracy. This approach is tested in previous studies and has proved to be effective and functional (Awotunde and Mutasiem, 2014; Jiang and Samuel, 2016).

By summating the results of this study and the literature, it could be concluded that the classic model of Bourgoyne and Young (1974) or its modified versions are suggested as the best choice for the cases that an analytical or semianalytical ROP model is being used for ROP management, either as the main approach or as an extra ROP prediction method for adopting performance comparison. This finding is validated by previous performance comparison studies, in which different ROP models are compared to each other. Also, a quick overview on Table 2 yields the same results, as this model (or its modified version) has showed proper results whenever implemented, recording the highest average prediction accuracy among all ROP models. Needless to say, for better comparison and judgment about different ROP models, the evaluated dataset for all of the articles should be uniform, which is a subject for future performance comparison studies.

It is also suggested to use Osguei and Özbayoğlu (2007) or Wiktorski et al. (2017) models (for drilling with RCB bits) or Kerkar et al. (2014) and Etesami et al. (2021) models (for drilling with PDC bits) to perform the ROP prediction process in horizontal and deviated wells. It is mainly because of defining new parameters (e.g., dogleg severity) to focus on the special conditions of these types of wells. In addition, Hareland and Hoberock (1993) model (modified Warren model) is also suggested to be used as the objective function of optimization algorithms (e.g., PSO). Even if the above suggestions have proved to be successful in most cases, still the necessity of a special expert system to examine different analytical and semi-analytical models in each field is being felt [such expert system was designed and successfully implemented by the authors (Najjarpour et al., 2020)].

The globalization of ROP management studies were also analyzed in this study. It should be noted that the basis for this analysis is the region or the field which ROP management is performed, but in the cases that this information were not stated clearly, the information from the authors' locations are used as the region of study. Moreover, only the research studies which have used the analytical, semi-analytical and empirical ROP models as the main approach for ROP management (listed in Table 6) are considered in this analysis. By considering these assumptions, Fig. 12 is created which shows the countries with the most ROP management studies among all the reviewed articles. USA, Iran, Brazil, Saudi Arabia, Canada, Norway and Iraq are among the countries in which these ROP management studies are conducted. The detailed information about the regions of such ROP management studies are shown in Table 6.

Final two analyses in this paper are about the distribution of different types of studies and also the share of each decade in these publications. For this purpose, three categories of journal articles, master or $\mathrm{PhD}$ thesis and conference papers are defined and all of the evaluated studies (listed in Table 6) are implemented in these categories. Fig. 13 shows the distribution of each publication source in ROP management 


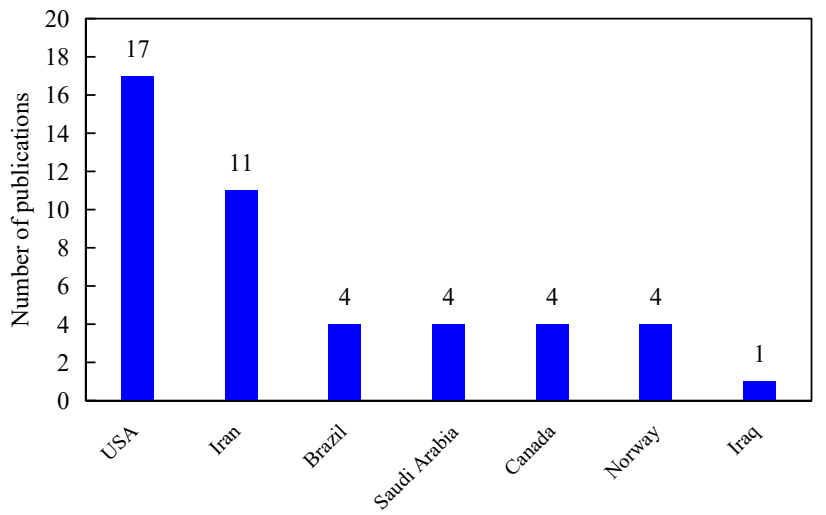

Fig. 12. List of countries with the most number of field management studies by using analytical, semi-analytical and empirical ROP models.

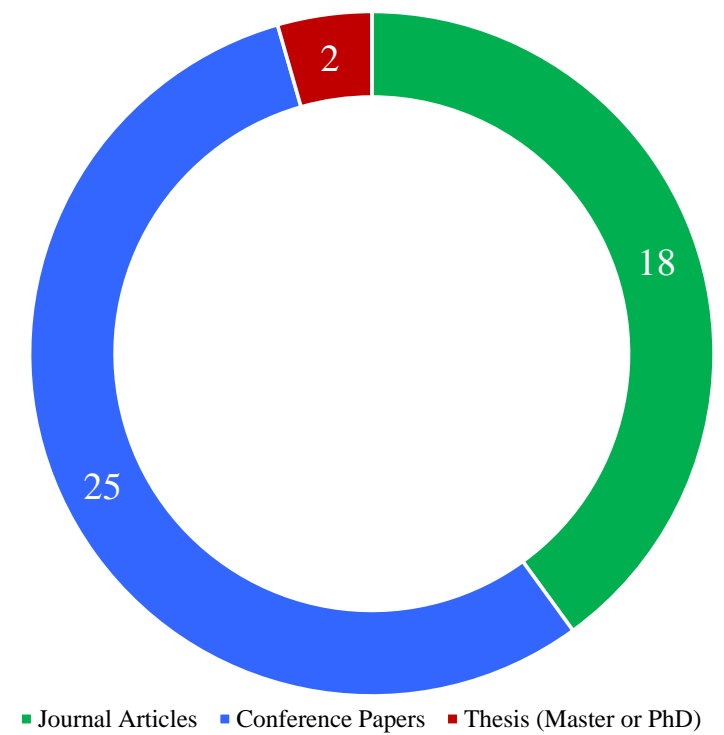

Fig. 13. Distribution of each publication source for the research studies which have used the analytical, semi-analytical and empirical models as the main approach for ROP management.

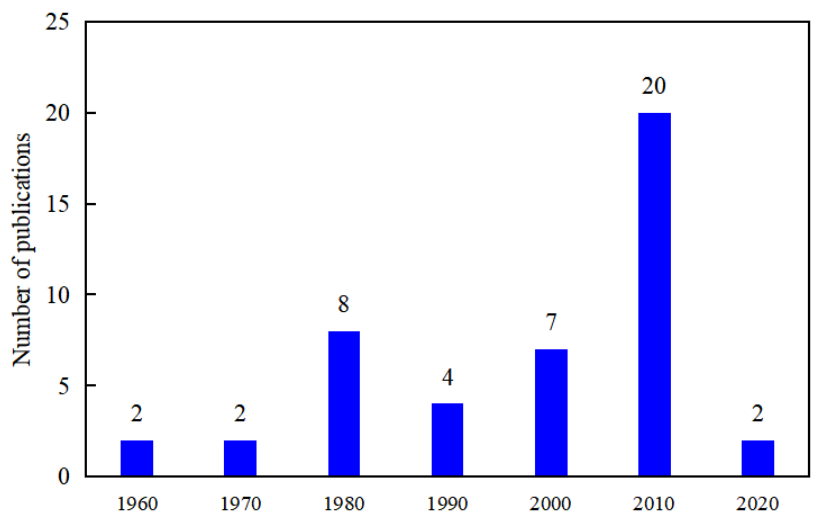

Fig. 14. Share of each decade in the research studies which have used the analytical, semi-analytical and empirical models as the main approach for ROP management.

studies which have used the analytical, semi-analytical and empirical ROP models as the main approach for ROP management, while Fig. 14 shows the share of each decade in these publications.

As it can be seen in Figs. 13 and 14, conference papers have been the most repeated source of publication for these articles, while they have been published in the previous decade (from 2010 to 2019) more than previous ones. By concentrating on Table 6 , it can also be excluded that the beginning and the ending years of this past decade (2010 and 2019) had had the highest amount of publications by using ROP models as the main approach of ROP management (each one with 4 studies). The analysis also shows that in spite of the fluctuations (between 80's and 90's), the general trend of publications in this category has been on the growth hitherto, and it is expected to grow even more in the current decade (from 2020 to 2029).

\section{Conclusions}

This study began with a description of the parameters affecting ROP and continued with explaining the history and formulation of several analytical, semi-analytical and empirical ROP models. Then, some of ROP management projects and studies which have used these models as the main approach for ROP prediction were reviewed. In addition, the reviewed performance comparison and field application studies by using these models as the extra method for ROP management were listed. The findings of this study can be summarized as below.

1) The model of Bourgoyne and Young (1974) is the most repeated model as the main approach for ROP management in previous studies, while Hareland and Hoberock (1993) (the modified Warren model) ranks in the second place.

2) The classic model of Bourgoyne and Young (1974) or its modified versions are suggested as the best choice for the cases that an analytical or semi-analytical ROP model is being used for ROP management, either as the main approach or as an extra ROP prediction method. Trustregion, progressive stochastic method and genetic algorithm are proper choices for determining the unknown coefficients of this ROP model.

3) For ROP prediction in deviated and horizontal wells, using the Osguei and Özbayoğlu (2007) and Wiktorski et al. (2017) models are proper choices, while Hareland and Hoberock (1993) model (modified Warren model) is also suggested to be used as the objective function of optimization algorithms.

By studying the previous articles related to the ROP models, it can be easily understood that the amount of work and effort put into this subject has been significant; however, there is no limit for this research topic and there are still lots of ways to go through in the future. For instance, application of these models for creating hybrid ROP prediction models as well as objective function of optimization algorithms still need to be improved in forthcoming studies. Moreover, models developed for horizontal and deviated wells do not take into account all special mechanisms of hole-cleaning in such wells, requiring better establishment in further research studies. It 
is foreseen by the authors that future ROP models are more prone to consider these research directions instead of trying to surpass pre-existed ROP models.

\section{Nomenclature}

$$
\begin{aligned}
& a=\text { model coefficient, dimensionless } \\
& a_{c}=\text { chip holddown permeability coefficient, dimension- } \\
& a_{i}=\text { model exponent, dimensionless } \\
& a_{s}=\text { stress confinement coefficient, dimensionless } \\
& \mathrm{Ar}=\text { relative abrasiveness, dimensionless } \\
& b=\text { model coefficient, dimensionless } \\
& b_{c}=\text { chip holddown permeability exponent, dimensionless } \\
& b_{s}=\text { formation permeability coefficient, dimensionless } \\
& c=\text { model coefficient, dimensionless } \\
& c_{c}=\text { chip holddown permeability constant, dimensionless } \\
& D_{b}=\text { bit diameter, in. } \\
& \text { ECD = equivalent circulating density, lbm/gal } \\
& f_{c}\left(P_{e}\right)=\text { chip holddown function, lbf } \\
& f_{i}=\text { model coefficient, dimensionless } \\
& F_{j}=\text { jet impact force, lbf } \\
& F_{j m}=\text { modified jet impact force, lbf } \\
& g_{p}=\text { pore pressure gradient, lbm/gal } \\
& h=\text { fractional bit tooth wear, dimensionless } \\
& H P_{b}=\text { bit hydraulic power (hp) } \\
& K=\text { formation drillability constant, dimensionless } \\
& N=\text { rotational speed, rev/min } \\
& P_{e}=\text { effective differential pressure, psi } \\
& Q=\text { flow rate, gal/min } \\
& \text { ROP = rate of penetration, ft/hr } \\
& S=\text { confined compressive strength, psi } \\
& S_{0}=\text { unconfined compressive strength, kPa } \\
& \text { SPP = standpipe pressure, psi } \\
& T=\text { drilling torque, ft-lbf } \\
& \mathrm{TVD}=\text { true vertical depth, } \mathrm{ft} \\
& \mathrm{UCS}=\text { uniaxial compressive strength, psi } \\
& W=\text { weight on bit, lbf } \\
& W_{c}=\text { wear coefficient, dimensionless } \\
& (W / D b t=T \text { to }
\end{aligned}
$$$$
\text { less }
$$$$
\left(W / D_{b}\right) t=\text { Threshold bit weight per inch of bit diameter }
$$$$
\text { where bit begins to drill, lbf/in }
$$$$
W_{f}=\text { bit wear function, dimensionless }
$$$$
x=\text { bit exponent, dimensionless }
$$$$
\Delta \mathrm{BG}=\text { change in bit tooth wear, dimensionless }
$$$$
\alpha=\text { siderake angle, degree }
$$$$
\theta=\text { backrake angle, degree }
$$$$
\gamma_{f}=\text { fluid specific gravity, dimensionless }
$$$$
\mu=\text { plastic viscosity, } \mathrm{cP}
$$$$
\rho=\text { mud density, } \mathrm{lbm} / \mathrm{gal}
$$

\section{List of Acronyms}

$$
\begin{aligned}
& \text { ANFIS = adaptive neuro-fuzzy inference system } \\
& \text { ANN }=\text { artificial neural network } \\
& \text { ECD }=\text { equivalent circulating density } \\
& \text { HHP }=\text { hydraulic horsepower } \\
& \text { PDC }=\text { polycrystalline diamond compact } \\
& \text { RCB }=\text { roller-cone bits } \\
& \text { ROP }=\text { rate of penetration }
\end{aligned}
$$

UCS = uniaxial compressive strength

WOB $=$ weight on bit

\section{Acknowledgement}

The authors would like to sincerely thank Dr. Hemmati Sarapardeh (Shahid Bahonar University of Kerman, Kerman, Iran) and Mr. Saeed Zabihi (National Iranian South Oilfields Company, Ahvaz, Iran) for their helps during this study.

\section{Conflict of interest}

The authors declare no competing interest.

Open Access This article is distributed under the terms and conditions of the Creative Commons Attribution (CC BY-NC-ND) license, which permits unrestricted use, distribution, and reproduction in any medium, provided the original work is properly cited.

\section{References}

Ahmed, A., Elkatatny, S., Ali, A., et al. Rate of penetration prediction in shale formation using fuzzy logic. Paper IPTC-19548 Presented at the International Petroleum Technology Conference, Beijing, China, 26-28 March, 2019.

Akbari, B., Butt, S., Munaswamy, K., et al. Dynamic single pdc cutter rock drilling modeling and simulations focusing on rate of penetration using distinct element method. Paper ARMA-11-379 Presented at the $45^{\text {th }}$ U.S. Rock Mechanics / Geomechanics Symposium, San Francisco, California, 26-29 June, 2011.

Al-AbdulJabbar, A., Elkatatny, S., Abdulhamid Mahmoud, A., et al. Prediction of the rate penetration while drilling horizontal carbonate reservoirs using a self-adaptive artificial neural network technique. Sustainability, 2020, 12(4): 1376.

Al-AbdulJabbar, A., Elkatatny, S., Mahmoud, M., et al. A robust rate of penetration model for carbonate formation. Journal of Energy Resources Technology, 2019, 141(4): 042903.

AlArfaj, I., Khoukhi, A., Eren, T. Application of advanced computational intelligence to rate of penetration prediction. Paper INSPEC 13244616 Presented at Computer Modeling and Simulation (EMS), 2012 Sixth UKSim/AMSS European Symposium on, Malta, Malta, 14-16 November, 2012.

Amar, K., Ibrahim, A. Rate of penetration prediction and optimization using advances in artificial neural networks, a comparative study. Paper INSPEC 13244616 Presented at $4^{\text {th }}$ International Joint Conference on Computational Intelligence, 14-16 November, 2012.

Amer, M. M., Dahab, A. S., El-Sayed, A. -A. H. An rop predictive model in nile delta area using artificial neural networks. Paper SPE 187969 Presented at SPE Kingdom of Saudi Arabia Annual Technical Symposium and Exhibition, Dammam, Saudi Arabia, 24-27 April, 2017.

Anemangely, M., Ramezanzadeh, A., Tokhmechi, B., et al. Drilling rate prediction from petrophysical logs and mud logging data using an optimized multilayer perceptron neural network. Journal of Geophysics and Engineering, 2018, 15(4): 1146-1159. 
Arabjamaloei, R., Karimi Dehkordi, B. Investigation of the most efficient approach of the prediction of the rate of penetration. Energy Sources, Part A: Recovery, Utilization, and Environmental Effects, 2012, 34(7): 581590.

Arabjamaloei, R., Shadizadeh, S. Modeling and optimizing rate of penetration using intelligent systems in an iranian southern oil field (ahwaz oil field). Petroleum Science and Technology, 2011, 29(16): 1637-1648.

Awotunde, A. A., Mutasiem, M. A. Efficient drilling time optimization with differential evolution. Paper SPE 172419 Presented at SPE Nigeria Annual International Conference and Exhibition, Lagos, Nigeria, 5-7 August, 2014.

Ayoub, M., Shien, G., Diab, D., et al. Modeling of drilling rate of penetration using adaptive neuro-fuzzy inference system. International Journal of Applied Engineering Research, 2017, 12(22): 12880-12891.

Bahari, A., Baradaran Seyed, A. Drilling cost optimization in iranian khangiran gas field. Paper SPE 108246 Presented at International Oil Conference and Exhibition in Mexico, Veracruz, Mexico, 27-30 June, 2007a.

Bahari, A., Baradaran Seyed, A. Trust-region approach to find constants of bourgoyne and young penetration rate model in khangiran iranian gas field. Paper SPE 107520 Presented at Latin American \& Caribbean Petroleum Engineering Conference, Buenos Aires, Argentina, 15-18 April, 2007b.

Bahari, M. H., Bahari, A., Moradi, H. Intelligent drilling rate predictor. International Journal of Innovative Computing, Information and Control, 2011, 7(2): 1511-1520.

Bani Mustafa, A., Abbas, A. K., Alsaba, M., et al. Improving drilling performance through optimizing controllable drilling parameters. Journal of Petroleum Exploration and Production, 2021, 11(3): 1223-1232.

Barbosa, L. F. F. M., Nascimento, A., Mathias, M. H., et al. Machine learning methods applied to drilling rate of penetration prediction and optimization-a review. Journal of Petroleum Science and Engineering, 2019, 183: 106332.

Bataee, M., Irawan, S., Kamyab, M. Artificial neural network model for prediction of drilling rate of penetration and optimization of parameters. Journal of the Japan Petroleum Institute, 2014, 57(2): 65-70.

Bataee, M., Kamyab, M., Ashena, R. Investigation of various rop models and optimization of drilling parameters for pdc and roller-cone bits in shadegan oil field. Paper SPE 130932 Presented at International Oil and Gas Conference and Exhibition in China, Beijing, China, 8-10 June, 2010.

Bezminabadi, S. N., Ramezanzadeh, A., Jalali, S. -M. E., et al. Effect of rock properties on rop modeling using statistical and intelligent methods: A case study of an oil well in southwest of iran. Archives of Mining Sciences, 2017, 62(1): 131-144.

Bourgoyne, A. T., Young, F. A multiple regression approach to optimal drilling and abnormal pressure detection. Society of Petroleum Engineers Journal, 1974, 14(4): 371-384.
Busahmin, B., Saeid, N. H., Alusta, G., et al. Review on hole cleaning for horizontal wells. Journal of Engineering and Applied Sciences, 2017, 12(16): 4697.

Caicedo, H., Calhoun, W., Ewy, R. Unique bit performance predictor using specific energy coefficients as a function of confined compressive strength impacts drilling performance. Paper SPE WPC 18 Presented at $18^{\text {th }}$ World Petroleum Congress, Johannesburg, South Africa, 25-29 September, 2005.

Chia, R., Smith, R. A new nozzle system to achieve high rop drilling. Paper SPE 15518 Presented at SPE Annual Technical Conference and Exhibition, New Orleans, Louisiana, 5-8 October, 1986.

Cho, H., Shah, S., Osisanya, S. A three-segment hydraulic model for cuttings transport in coiled tubing horizontal and deviated drilling. Journal of Canadian Petroleum Technology, 2002, 41(6): 32-39.

Conn, A. R., Gould, N. I., Toint, P. L. Trust Region Methods. Philadelphia, USA, Siam, 2000.

Diaz, M. B., Kim, K. Y., Kang, T. -H., et al. Drilling data from an enhanced geothermal project and its pre-processing for rop forecasting improvement. Geothermics, 2018, 72: 348-357.

Duklet, C. P., Bates, T. R. An empirical correlation to predict diamond bit drilling rates. Paper SPE 9324 Presented at SPE Annual Technical Conference and Exhibition, Dallas, Texas, 21-24 September, 1980.

Eberhart, R. C., Shi, Y. Comparison between genetic algorithms and particle swarm optimization. Paper Presented at International conference on evolutionary programming, San Diego, CA, USA, 25-27 March, 1998.

Eckel, J. R. Microbit studies of the effect of fluid properties and hydraulics on drilling rate. Journal of Petroleum Technology, 1967, 19(4): 541-546.

Elahifar, B., Thonhauser, G., Fruhwirth, R. K., et al. Rop modeling using neuralnetwork and drill string vibration data. Paper SPE 163330 Presented at SPE Kuwait International Petroleum Conference and Exhibition, Kuwait City, Kuwait, 10-12 December, 2012.

Elkatatny, S. New approach to optimize the rate of penetration using artificial neural network. Arabian Journal for Science and Engineering, 2017, 43(11): 6297-6304.

Elkatatny, S. Development of a new rate of penetration model using self-adaptive differential evolution-artificial neural network. Arabian Journal of Geosciences, 2019, 12(2): 19.

Elkatatny, S. Real-time prediction of rate of penetration in s-shape well profile using artificial intelligence models. Sensors, 2020, 20(12): 3506.

Elkatatny, S., Al-AbdulJabbar, A., Abdelgawad, K. A new model for predicting rate of penetration using an artificial neural network. Sensors, 2020, 20(7): 2058.

Eren, T., Ozbayoglu, M. E. Real time optimization of drilling parameters during drilling operations. Paper SPE 129126 Presented at the SPE Oil and Gas India Conference and Exhibition, Mumbai, India, 20-22 January, 2010.

Etesami, D., Shirangi, M., Zhang, W. A semiempirical model for rate of penetration with application to an offshore gas 
field. SPE Drilling \& Completion, 2021, 36(1): 29-46.

Fear, M. How to improve rate of penetration in field operations. SPE Drilling \& Completion, 1999, 14(1): 42-49.

Formighieri, S., Freitas, P. J. d. F. Estimation of bourgoyne and young model coefficients using markov chain monte carlo simulation. Paper INSPEC 15800161 Presented at 2015 Winter Simulation Conference (WSC), Huntington Beach, CA, USA, 6-9 December, 2015.

Galle, E., Woods, H. Best constant weight and rotary speed for rotary rock bits. Paper API 63 Presented at Drilling and Production Practice, New York, USA, 1 January, 1963.

Guria, C., Goli, K. K., Pathak, A. K. Multi-objective optimization of oil well drilling using elitist nondominated sorting genetic algorithm. Petroleum Science, 2014, 11(1): 97-110.

Hadi, F., Altaie, H., AlKamil, E. Modeling rate of penetration using artificial intelligent system and multiple regression analysis. Paper SPE 197663 Presented at the Abu Dhabi International Petroleum Exhibition \& Conference, Abu Dhabi, UAE, 11-14 November, 2019.

Hareland, G., Hoberock, L. Use of drilling parameters to predict in-situ stress bounds. Paper SPE 25727 Presented at SPE/IADC Drilling Conference, Amsterdam, Netherlands, 22-25 February, 1993.

Hareland, G., Nygaard, R. Calculating unconfined rock strength from drilling data. Paper ARMA 07 Presented at 1st Canada-US Rock Mechanics Symposium, Vancouver, Canada, 27-31 May, 2007.

Hareland, G., Rampersad, P. R. Drag-bit model including wear. Paper SPE 26957 Presented at the SPE Latin America/Caribbean Petroleum Engineering Conference, Buenos Aires, Argentina, 27-29 April, 1994.

Hareland, G., Wu, A., Rashidi, B. A drilling rate model for roller cone bits and its application. Paper SPE 129592 Presented at International Oil and Gas Conference and Exhibition in China, Beijing, China, 8-10 June, 2010.

Hassan, K. H., Hussien, H. A. H. A. Optimization of drilling parameters with aid of real time data for buzargan oil field. IOP Conference Series: Materials Science and Engineering, 2019, 579: 012003.

Hegde, C., Daigle, H., Millwater, H., et al. Analysis of rate of penetration (rop) prediction in drilling using physicsbased and data-driven models. Journal of Petroleum Science and Engineering, 2017, 159: 295-306.

Hegde, C., Gray, K. E. Use of machine learning and data analytics to increase drilling efficiency for nearby wells. Journal of Natural Gas Science and Engineering, 2017, 40: 327-335.

Hegde, C., Millwater, H., Pyrcz, M., et al. Rate of penetration (rop) optimization in drilling with vibration control. Journal of Natural Gas Science and Engineering, 2019, 67: 71-81.

Hegde, C., Soares, C., Gray, K. Rate of penetration (rop) modeling using hybrid models: Deterministic and machine learning. Paper Presented at Unconventional Resources Technology Conference, Houston, Texas, 23-
25 July, 2018

Hegde, C., Wallace, S., Gray, K. Using trees, bagging, and random forests to predict rate of penetration during drilling. Paper SPE 176792 Presented at the SPE Middle East Intelligent Oil and Gas Conference and Exhibition, Abu Dhabi, UAE, 15-16 September, 2015.

Holland, J. H. Adaptation in Natural and Artificial Systems: An Introductory Analysis with Applications to Biology, Control, and Artificial Intelligence. Massachusetts, USA, The MIT Press, 1992.

Jiang, W., Samuel, R. Optimization of rate of penetration in a convoluted drilling framework using ant colony optimization. Paper SPE 178847 Presented at IADC/SPE Drilling Conference and Exhibition, Fort Worth, Texas, USA, 1-3 March, 2016.

Kerkar, P. B., Hareland, G., Fonseca, E. R., et al. Estimation of rock compressive strength using downhole weight-on-bit and drilling models. Paper IPTC 17447 Presented at IPTC 2014: International Petroleum Technology Conference, Doha, Qatar, 19-22 January, 2014.

Khosravanian, R., Choodar, B., Wood, D. A., et al. Rop fuzzy-logic model proposed for intelligent drilling in iran, malaysia. Oil \& Gas Journal, 2016, 114(11): 58-61.

Kor, K., Altun, G. Is support vector regression method suitable for predicting rate of penetration? Journal of Petroleum Science and Engineering, 2020, 194: 107542.

Kutas, D., Nascimento, A., Elmgerbi, A., et al. A study of the applicability of bourgoyne \& young rop model and fitting reliability through regression. Paper IPTC 18521 Presented at International Petroleum Technology Conference, Doha, Qatar, 6-9 December, 2015.

Liu, Z., Marland, C., Li, D., et al. An analytical model coupled with data analytics to estimate pdc bit wear. Paper SPE 169451 Presented at SPE Latin America and Caribbean Petroleum Engineering Conference, Maracaibo, Venezuela, 21-23 May, 2014.

Maidla, E., Ohara, S. Field verification of drilling models and computerized selection of drill bit, wob, and drillstring rotation. SPE Drilling Engineering, 1991, 6(3): 189-195.

Mammadov, E., Osayande, N., Breuer, J., et al. Predicting and optimizing rop in competent shale by utilizing mpd technology. Paper SPE 174805 Presented at SPE Annual Technical Conference and Exhibition, Houston, Texas, USA, 28-30 September, 2015.

Manshad, A. K., Rostami, H., Toreifi, H., et al. Improvement of drilling penetration rate in oil fields using a psoga-mlp hybrid network, in Heavy Oil, edited by A. H. Mohammadi, Nova Science Publishers, New York, pp. 271-284, 2017.

Mantha, B., Samuel, R. Rop optimization using artificial intelligence techniques with statistical regression coupling. Paper SPE 181382 Presented at SPE Annual Technical Conference and Exhibition, Dubai, UAE, 2628 September, 2016.

Mathis, W., Thonhauser, G., Wallnoefer, G., et al. Use of realtime rig-sensor data to improve daily drilling reporting, benchmarking, and planning - a case study. SPE Drilling \& Completion, 2007, 22(3): 217-226. 
Maurer, W. The "perfect-cleaning" theory of rotary drilling. Journal of Petroleum Technology, 1962, 14(11): 12701274.

Mensa-Wilmot, G., Langdon, S. P., Harjadi, Y. Drilling efficiency and rate of penetration: Definitions, influencing factors, relationships, and value. Paper SPE 128288 Presented at IADC/SPE Drilling Conference and Exhibition, New Orleans, Louisiana, USA, 2-4 February, 2010.

Moradi, H., Bahari, M. H., Sistani, M. B. N., et al. Drilling rate prediction using an innovative soft computing approach. Scientific Research and Essays, 2010, 5(13): 1583-1588.

Moré, J. J., Sorensen, D. C. Computing a trust region step. SIAM Journal on Scientific and Statistical Computing, 1983, 4(3): 553-572.

Mostofi, M., Shahbazi, K., Rahimzadeh, H., et al. Drilling optimization based on the rop model in one of the iranian oil fields. Paper SPE 131349 Presented at International Oil and Gas Conference and Exhibition in China, Beijing, China, 8-10 June, 2010.

Motahhari, H. R., Hareland, G., James, J. Improved drilling efficiency technique using integrated pdm and pdc bit parameters. Journal of Canadian Petroleum Technology, 2010, 49(10): 45-52.

Najjarpour, M., Jalalifar, H. Optimization of fairhurst-cook model for 2-d wing cracks using ant colony optimization (aco), particle swarm intelligence (pso), and genetic algorithm (ga). Journal of Applied Mathematics and Physics, 2018, 6(8): 1581.

Najjarpour, M., Jalalifar, H., Apourvari, S. N. The effect of formation thickness on the performance of deterministic and machine learning models for rate of penetration management in inclined and horizontal wells. Journal of Petroleum Science and Engineering, 2020, 191: 107160.

Nascimento, A., Tamas Kutas, D., Elmgerbi, A., et al. Mathematical modeling applied to drilling engineering: An application of bourgoyne and young rop model to a presalt case study. Mathematical Problems in Engineering, 2015, 2015: 631290.

Nygaard, R., Hareland, G. Application of rock strength in drilling evaluation. Paper SPE 106573 Presented at Latin American \& Caribbean Petroleum Engineering Conference, Buenos Aires, Argentina, 15-18 April, 2007.

Osgouei, R. E., Özbayoğlu, M. Rate of penetration estimation model for directional and horizontal wells. Middle East Technical University, Ankara, Turkey, 2007.

Mirzaei-Paiaman, A., Al-Askari, M., Salmani, B., et al. Effect of drilling fluid properties on rate of penetration. Nafta, 2009, 60(3): 129-134.

Peterson, J. Diamond drilling model verified in field and laboratory tests. Journal of Petroleum Technology, 1976, 28(2): 213-222.

Rahimzadeh, H., Mostofi, M., Hashemi, A. A new method for determining bourgoyne and young penetration rate model constants. Petroleum Science and Technology, 2011, 29(9): 886-897.

Rahmanifard, H., Plaksina, T. Application of artificial intelligence techniques in the petroleum industry: A review. Artificial Intelligence Review, 2018, 52(4): 2295-
2318.

Rampersad, P., Hareland, G., Boonyapaluk, P. Drilling optimization using drilling data and available technology. Paper SPE 27034 Presented at SPE Latin America/Caribbean Petroleum Engineering Conference, Buenos Aires, Argentina, 27-29 April, 1994.

Rastegar, M., Hareland, G., Nygaard, R., et al. Optimization of multiple bit runs based on rop models and cost equation: A new methodology applied for one of the persian gulf carbonate fields. Paper SPE 114665 Presented at IADC/SPE Asia Pacific Drilling Technology Conference and Exhibition, Jakarta, Indonesia, 25-27 August, 2008.

Seifabad, M. C., Ehteshami, P. Estimating the drilling rate in ahvaz oil field. Journal of Petroleum Exploration and Production Technology, 2013, 3(3): 169-173.

Shi, X., Liu, G., Gong, X., et al. An efficient approach for real-time prediction of rate of penetration in offshore drilling. Mathematical Problems in Engineering, 2016, 2016: 3575380 .

Shirkavand, F., Hareland, G., Aadnoy, B. Rock mechanical modelling for a underbalanced drilling rate of penetration prediction. Paper ARMA 09 Presented at $43^{\text {rd }}$ US Rock Mechanics Symposium \& $4^{\text {th }}$ US-Canada Rock Mechanics Symposium, Asheville, North Carolina, 28 June-1 July, 2009.

Soares, C., Daigle, H., Gray, K., et al. Evaluation of pdc bit rop models and the effect of rock strength on model coefficients. Journal of Natural Gas Science and Engineering, 2016, 34: 1225-1236.

Soares, C., Gray, K. Real-time predictive capabilities of analytical and machine learning rate of penetration (rop) models. Journal of Petroleum Science and Engineering, 2019, 172: 934-959.

Sorensen, D. Trust-region methods for unconstrained minimization. Paper Presented at NATO Advanced Research Institute conference on nonlinear optimization, Cambridge, UK, 13 July, 1981.

Sui, D., Nyboe, R., Azizi, V. Real-time optimization of rate of penetration during drilling operation. Paper INSPEC 13679818 Presented at $201310^{\text {th }}$ IEEE International Conference on Control and Automation (ICCA), Hangzhou, China, 12-14 June, 2013.

Tewari, S., Dwivedi, U. D. A novel neural network framework for the prediction of drilling rate of penetration. Paper Presented at APCEC 17 International Conference on Advances in Petroleum, Chemical \& Energy Challenges, RGIPT, Amethi, Jais, Uttar Pradesh, India, March, 2017.

Walker, B., Black, A., Klauber, W., et al. Roller-bit penetration rate response as a function of rock properties and well depth. Paper SPE 15620 Presented at SPE Annual Technical Conference and Exhibition, New Orleans, Louisiana, 5-8 October, 1986.

Warren, T. Drilling model for soft-formation bits. Journal of Petroleum Technology, 1981, 33(6): 963-970.

Warren, T. Penetration rate performance of roller cone bits. SPE Drilling Engineering, 1987, 2(1): 9-18.

Whitley, D. A genetic algorithm tutorial. Statistics and Computing, 1994, 4(2): 65-85. 
Wiktorski, E., Kuznetcov, A., Sui, D. Rop optimization and modeling in directional drilling process. Paper SPE 185909 Presented at the SPE Bergen One Day Seminar, Bergen, Norway, 5 April, 2017.

Winters, W., Warren, T., Onyia, E. Roller bit model with rock ductility and cone offset. Paper SPE 16696 Presented at SPE Annual Technical Conference and Exhibition, Dallas, Texas, 27-30 September, 1987.

Wojtanowicz, A. K., Kuru, E. Dynamic drilling strategy for pdc bits. Paper SPE 16118 Presented at SPE/IADC Drilling Conference, New Orleans, Louisiana, 15-18 March, 1987.
Xiao, L., Zhang, T. A proximal stochastic gradient method with progressive variance reduction. SIAM Journal on Optimization, 2014, 24(4): 2057-2075.

Yavari, H., Sabah, M., Khosravanian, R., et al. Application of an adaptive neuro-fuzzy inference system and mathematical rate of penetration models to predicting drilling rate. Iranian Journal of Oil \& Gas Science and Technology, 2018, 7(3): 73-100.

Yi, P., Kumar, A., Samuel, R. Realtime rate of penetration optimization using the shuffled frog leaping algorithm. Journal of Energy Resources Technology, 2015, 137(3): 032902. 